\title{
3D-clinorotation induces specific alterations in metabolite profiles of germinating Brassica napus L. seeds
}

\section{Veronika Chantseva ${ }^{1,2}$, Tatiana Bilova ${ }^{1,3}$, Galina Smolikova ${ }^{1}$, Andrej Frolov ${ }^{2,3}$, and Sergei Medvedev ${ }^{1}$}

1Department of Plant Physiology and Biochemistry, Faculty of Biology, Saint Petersburg State University, Universitetskaya nab., 7-9, Saint Petersburg, 199034, Russian Federation

2Department of Biochemistry, Faculty of Biology, Saint Petersburg State University, Srednii prosp., 41-43, Saint Petersburg, 199004, Russian Federation

${ }^{3}$ Department of Bioorganic Chemistry, Weinberg 3, 06120 Halle/Saale DE, Leibniz Institute of Plant Biochemistry, Germany

Address correspondence and requests for materials to Sergei Medvedev, s.medvedev@spbu.ru

\begin{abstract}
During the whole history of their life on Earth, higher plants evolved under the constant gravity stimulus. Therefore, plants developed efficient mechanisms of gravity perception, underlying their ability to adjust the direction of growth to the gravity vector, i. e. the phenomenon of gravitropism. In this context, alterations in the magnitude and vector of the gravity field might compromise plant growth and development. This aspect was successfully addressed in gravity fields of low intensity (microgravity). On the other hand, microgravity can be simulated on the Earth by clinorotation, i. e. rotation of the experimental plant along one or several axes. This approach is routinely used for studies of gravityrelated responses of crop plants, although the effect of simulated microgravity on the most sensitive ontogenetic stages - germination and seedling development - is still not sufficiently characterized. Recently, we addressed the effects of clinorotation on the proteome of germinating oilseed rape (Brassica napus) seeds. Here we extend this study to the seedling primary metabolome and address its changes in the presence of 3D-clinorotation. GC-MS analysis revealed essential alterations in patterns of sugars and sugar phosphates (specifically glucose-6-phosphate), methionine and glycerol. Thereby, abundances of individual metabolites showed high dispersion, indicating high lability and plasticity of the seedling metabolome.
\end{abstract}

Keywords: Brassica napus, clinorotation, 3D-clinostat, metabolomics, primary metabolites, seed germination, simulated microgravity.

\section{Introduction}

Gravitation is one of the most important factors permanently affecting all terrestrial organisms, including higher plants (Dubinin and Vaulina, 1976). The gravity field defines the direction of plant growth and axial symmetry of plant organs, directly affecting their organization (Medina and Herranz, 2010; Medvedev, 2012; Medvedev, 2018). On another hand, the polar organization of the organs of higher plants resulted in the development of efficient and highly sensitive gravity perception mechanisms, underlying the ability to adjust the direction of their growth to the gravity vector, i. e. the phenomenon of gravitropism (Morita, 2010; Wyatt and Kiss, 2013; Sato et al., 2015; Kolesnikov et al., 2015).

The effects of alterations in the magnitude and direction of the gravity field on plants have been intensively studied by plant physiologists during the last decade (Herranz et al., 2013; Kordyum, 2014). Thus, development of plants in 
low-intensity gravity fields (i.e. microgravity) was successfully addressed by the methods of space biology established in inhabited orbital stations (Hoson et al., 2014; Zheng et al., 2015; Vandenbrink and Kiss, 2016). It was shown that model (Arabidopsis) and crop plants (cabbage, wheat, pea) were able to complete their life cycle under microgravity conditions (Sychev et al., 2007; Vandenbrink and Kiss, 2016), although clear adverse effects on plant development and productivity could be observed (Paul et al., 2013; De Micco et al., 2014; Zheng et al., 2015). Typically, the effects of microgravity were manifested as retardation of plant growth and development, accompanied with dramatic changes at the subcellular level (Sychev et al., 2007; Wolverton and Kiss, 2009; Popova et al., 2009; Popova and Ivanenko, 2010). Thereby, the weights and numbers of seeds formed under these conditions were slightly reduced in comparison to ground control (Kordyum, 2014).

Although microgravity can be easily established at space stations, in orbital experiments its effects cannot be clearly distinguished from the impact of accompanying factors, like high ethylene content, absence of air convection, limited accessible volume available for growth expansion, and space irradiation (Vandenbrink and Kiss, 2016). This limitation can be, however, to some extent overcome by performing experiments on Earth under continuous change of the plant position in space relative to the gravity vector, i. e. under conditions of simulated microgravity (Herranz et al., 2013). In the easiest and most straightforward way, simulated microgravity can be established by clinorotation, i. e. rotation of the experimental plant along one or several axes with the angular velocity of 1 to $10 \mathrm{rpm}$ (Kordyum, 1997; Herranz et al., 2013). To avoid confusion, the term "simulated microgravity" (analogous to microgravity conditions in spaceflight) is often used for such experiments (Kordyum, 1997; Herranz et al., 2013). Microgravity simulation by means of continuous change of orientation of objects relative to the gravity's vector can generate effects comparable to the effects of true microgravity (Borst and van Loon, 2009). Clinostats with two axes are known as three-dimensional (3-D) clinostats or "Random positioning machines". These 3-D systems have two independently rotating frames (van Loon, 2007). The continuous rotation doesn't allow perception of gravitational stimulus by the plant, as its position constantly changes relative to the vector of Earth's gravity, resembling thereby conditions of true microgravity (Herranz et al., 2013; Kordyum, 2014). Thus, clinorotation is an efficient technique that might give deep insight into the impact of gravity on the physiology of higher plants at molecular, cellular and organism levels (Wang et al., 2016).

To date, an essential body of experimental data on the effects of clinorotation on plant development has been collected (Kordyum, 1997; Wei et al., 2010; Jagtap et al., 2011). The research was mostly focused on the changes in plant anatomy and physiology related to the loss of gravity vector; accompanying alterations in seed development (Popova and Ivanenko, 2010), organ differentiation (Popova et al., 2009; Wei et al., 2010); as well as dynamics of cell proliferation (Matía et al., 2009; Manzano et al., 2009) and differentiation (Kordyum, 2014). However, the data on the influence of clinorotation on the metabolism of germinated seeds is limited.

During the recent decade, these aspects were comprehensively addressed by the methods of functional genomics. The profiles of gene expression (Aubry-Hivet et al., 2014; Inglis et al., 2014) and protein dynamics (Zupanska et al., 2013; Mazars et al., 2014) were comprehensively characterized in plant seedlings, organs and tissues. Thereby the genes involved in oxidative stress, calcium signaling and response to abiotic and biotic stressors were shown to be affected by microgravity (Paul et al., 2012; Correll et al., 2013; Krishnamurthy et al., 2018). At the proteomic level, these expressional changes were accompanied by alterations in antioxidative defense, signaling and primary metabolism (Barjaktarović et al., 2007; Barjaktarović et al., 2009).

However, to date, it becomes obvious that in characterization of microgravity-related effects, special attention needs to be paid to identification of the developmental stages most sensitive to the effects of simulated microgravity, with a special emphasis on embryogenesis and seed germination (Kordyum, 2014). Accordingly, we recently characterized the changes in the proteome of germinating oilseed rape seeds, observed under the conditions of microgravity, simulated by 3D-clinorotation (Frolov et al., 2018). Here we extend this study to the seed metabolome and address alterations in the pattern of primary metabolites in germinating B.napus seeds in context of the accompanying changes in their redox status.

\section{Material and methods}

\section{REAGENTS AND PLANT MATERIAL}

Unless stated otherwise, materials were obtained from the following manufacturers: Reachem (Moscow, Russia): sodium carbonate (p.a.); Vekton (Saint Petersburg, Russia): thiobarbituric acid (p. a.), methanol (LC grade), perchloric acid (p.a.). All other chemicals were purchased from Sigma-Aldrich Chemie GmbH (Taufkirchen, Germany). Water was purified in house (resistance $>18 \mathrm{~m} \Omega / \mathrm{cm}$ ) on a water conditioning and purification system UVOI-MF1-NA(18)-N (Mediana-Filtr, Moscow, Russia). The seeds of oilseed rape (Brassica napus L, cultivar Yubileiny) were obtained from the collection of the oilseed laboratory of the Federal Research Center of the Vavilov Russian Institute of Plant Genetic Resources (\# k-5285). 


\section{PLANT EXPERIMENTS}

The seeds were planted in $35 \mathrm{~mm}$ Petri dishes (25 seeds per plate), filled with aqueous (aq.) $0.8 \%$ (w/v) agar medium. Immediately after planting, the plates were covered with lids, insulated from light with aluminum foil and secured with double-sided tape on a 3D clinostat (in total, six per run) designed as described elsewhere (Frolov et al., 2018). The seeds were germinated under continuous rotation at $2.5 \mathrm{rpm}$ around each of the two axes of the clinostat (Supplementary information, Figure S1). The seeds germinated under static conditions served as controls. The seedlings were harvested after 24 hours or 48 hours, shock-frozen in liquid nitrogen and ground in a ball mill (Retsch MM 400, Haan, Germany) with $3 \mathrm{~mm}$ stainless steel balls at a vibration frequency of $30 \mathrm{~Hz}$ for $2 \times 1 \mathrm{~min}$. The obtained fine frozen powder was aliquoted for individual biochemical tests and metabolomics experiments, and stored at $-80^{\circ} \mathrm{C}$ before analysis.

\section{DETERMINATION OF SEED QUALITY}

The quality of the seeds germinated in the presence and absence of clinorotation was determined according to the standards of the International Seed Testing Association (ISTA) (ISTA, 2003). For this, the seeds of the experimental and control groups $(n=3 \times 25)$, germinated for 24 and 48 hours, were transferred to wet filter paper, placed in a climate chamber, and grown for five days at $22^{\circ} \mathrm{C}$. On the sixth day, the number of normally and abnormally (i.e. those with short, curved, or abnormally thick hypocotyls/roots) developed seedlings was assessed.

\section{ANALYSIS OF LIPID PEROXIDATION}

The levels of lipid peroxidation were assessed by the contents of thiobarbituric acid (TBA)-reactive substances as described by Frolov et al. (2017) with some modifications. Specifically, $400 \mu \mathrm{L}$ of ice-cold $5 \%$ (w/v) trichloroacetic acid (TCA) in $\mathrm{dH}_{2} \mathrm{O}$ were added to the aliquots (approximately $30 \mathrm{mg}$ ) of frozen plant material. The suspensions were thoroughly vortexed ( $3000 \mathrm{~g}, 30 \mathrm{~s}$ ) and centrifuged $\left(4^{\circ} \mathrm{C}, 10000 \mathrm{~g}, 20 \mathrm{~min}\right)$. The supernatants were transferred to pre-chilled $2 \mathrm{~mL}$ polypropylene tubes and supplemented with $1.4 \mathrm{~mL}$ of $0.5 \%(\mathrm{w} / \mathrm{v}) \mathrm{TBA}$ in a $20 \%(\mathrm{w} / \mathrm{v}) \mathrm{TCA}$ in $\mathrm{dH}_{2} \mathrm{O}$. After vortexing $(3000 \mathrm{~g}$, $30 \mathrm{~s}$ ), the mixtures were incubated for $30 \mathrm{~min}$ at $95^{\circ} \mathrm{C}$, cooled to room temperature, transferred to polypropylene cuvettes, and the absorbance of the solutions was recorded at 532 and $600 \mathrm{~nm}$. The concentration of $1: 2 \mathrm{col}-$ ored malondialdehyde (MDA): TBA complex was calculated from the difference between the values of specific $(532 \mathrm{~nm})$ and non-specific $(600 \mathrm{~nm})$ absorption. The contents of lipid peroxidation products were calculated as equivalents of $\mathrm{MDA}\left(\varepsilon=155 \mathrm{mmol} / \mathrm{L}^{-1} \mathrm{~cm}^{-1}\right)$.

\section{DETERMINATION OF ASCORBATE CONTENTS}

Ascorbic and dehydroascorbic acids (Asc and DHA, respectively) were quantified in ground seedling material using an adaption of the method described by Paudel et al (2016). Specifically, $50 \mathrm{mg}$ of frozen plant material were left on ice for $3 \mathrm{~min}$ before $0.5 \mathrm{~mL}$ of ice-cold $\mathrm{HClO}_{4}$ $(2.5 \mathrm{~mol} / \mathrm{L})$ was added. The suspensions were vortexed for $30 \mathrm{~s}$ and centrifuged $\left(10 \mathrm{~min}, 12000 \mathrm{~g}, 4^{\circ} \mathrm{C}\right)$. The supernatants were transferred to new polypropylene tubes, neutralized with saturated $\mathrm{Na}_{2} \mathrm{CO}_{3}$ solution and diluted 10 -fold with $0.1 \mathrm{~mol} / \mathrm{L}$ sodium phosphate buffer ( $\mathrm{pH} 5.6$ ). For determination of ascorbic acid, $500 \mu \mathrm{L}$ of the diluted extract was placed in a quartz cuvette and the absorbance at $265 \mathrm{~nm}$ was recorded before $1 \mathrm{U}$ of ascorbate oxidase ( $1 \mu \mathrm{L}$ in $4 \mathrm{mmol} / \mathrm{L}$ sodium phosphate buffer, $\mathrm{pH}$ 5.6) was added. Afterwards, the absorbance was recorded at the same wavelength after 2 min incubation at room temperature (RT). The total ascorbate was quantified after reduction of diluted extract with DTT $(3 \mu \mathrm{L}$ of $3 \mathrm{~mol} / \mathrm{L}$ solution) for $1 \mathrm{~min}$ on ice at the same wavelength. Dehydroascorbic acid was calculated as the difference between the total ascorbate and ascorbic acid contents.

\section{METABOLITE PROFILING}

Profiling of polar primary metabolites relied on watermethanol extraction as described by Bilova et al (2016; 2017 ) with minor modifications. Specifically, portions of frozen plant material (approximately $50 \mathrm{mg}$ ) in $1.5 \mathrm{~mL}$ polypropylene tubes were supplemented with $800 \mu \mathrm{L}$ of ice-cold methanol. The suspensions were vortexed (3000 g, $30 \mathrm{~s})$, centrifuged $\left(4^{\circ} \mathrm{C}, 15000 \mathrm{~g}, 10 \mathrm{~min}\right)$, and $500 \mu \mathrm{L}$ of supernatants were transferred to new $1.5 \mathrm{~mL}$ tubes. The residues were supplemented with $400 \mu \mathrm{L}$ of MilliQ water, vortexed (3000 g, $30 \mathrm{~s}$ ), and centrifuged $\left(4^{\circ} \mathrm{C}, 15000 \mathrm{~g}, 10 \mathrm{~min}\right)$. The resulted supernatants $(600 \mu \mathrm{L})$ were combined with the first portion, and the total extract was delipidated by supplementation of $n$-hexane $(300 \mu \mathrm{L})$ and vortexing (3000 g, $30 \mathrm{~s})$. After centrifugation $\left(4^{\circ} \mathrm{C}, 15000 \mathrm{~g}, 5 \mathrm{~min}\right)$, aliquots $(50 \mu \mathrm{L})$ of the aqueous phases were saved in new $1.5 \mathrm{~mL}$ polypropylene tubes and evaporated to dryness under reduced pressure at $4{ }^{\circ} \mathrm{C}$. The residues were step-wise derivatized with methoxyamine hydrochloride (MOA) and $\mathrm{N}, \mathrm{O}$-bis(trimethylsilyl)trifluoroacetamide (BSTFA) according to the procedure of Milkovska-Stamenova et al (2015). One $\mu \mathrm{L}$ of sample was injected (splitless mode, $90 \mathrm{~s}$, injector temperature was set to $250^{\circ} \mathrm{C}$ ) with Agilent G4513A autosampler in an Agilent GC 8650 gas chromatograph coupled online to a quadrupole mass selective detector Agilent 5975BVLMSD (Agilent Technologies, Santa Clara, CA, USA), controlled by Agilent ChemStation E. 02.02.1431 software (Agilent Technologies, Inc., USA). The separation relied on a HP- 5 capillary column (Agilent Technologies, Santa Clara, CA, USA) with he- 
lium used as a carrier gas $(1 \mathrm{~mL} / \mathrm{min})$ and temperature gradient from 70 to $320^{\circ} \mathrm{C}$ with a ramp $5^{\circ} \mathrm{C} / \mathrm{min}$, as described by Pozhvanov et al (2017). Electron impact ionization was accomplished at $70 \mathrm{eV}$ and $250^{\circ} \mathrm{C}$. The quadrupole was operated in a scanning mode in the $m / z$ range 50-550 with the scanning at $0.34 \mathrm{sec} \mathrm{scan}^{-1}$.

\section{DATA PROCESSING}

For identification of analytes, the raw data were converted in cdf format using OpenChrom software (version 1.1.0; https://www.openchrom.net/). Annotation of metabolites and deconvolution of spectra relied on the Automated Mass Spectral Deconvolution \& Identification System (AMDIS, version 32). Identification of analytes was accomplished by similarity search of deconvoluted spectra against spectral libraries National Institute of Standards and Technology (NIST08), Golm metabolome database (GMB, 17.02.2017) and in-house library based on the spectra of authentic standards). For quantitative analysis, the cdf files were imported in Xcalibur 2.0.7 software and converted in raw format. Individual analytes were quantified by integration of the areas of corresponding peaks at extracted ion chromatograms (XICs), calculated for characteristic $m / z \pm 0.5$ and retention times $\left(\mathrm{t}_{\mathrm{R}}\right)$. For lowabundant metabolites, quantification relied on the standard addition method, as described by Bilova et al (2016; 2017), whereas quantitative analysis of highly-abundant metabolites was based on external standardization in the range from $0.2 \mathrm{pmol} / \mathrm{L}$ to $0.2 \mathrm{nmol} / \mathrm{L}$. The microgravityrelated differences in metabolite profiles were characterized by principal component analysis (PCA).

\section{STATISTICS}

Statistical significance of the observed clinorotation-related differences was assessed by Student's t-test using the Microsoft Excel platform. The false discovery rate (FDR) was calculated for the confidence level of $\mathrm{p}<0.05$ by the Benjamini-Hochberg method (Benjamini and Hochberg, 1995; Jeong et al., 2012). Metabolite profiles were evaluated by PCA and partial least squares discriminant analysis (PLS-DA) using the online resource Metaboanalyst 4.0 (http://www.metaboanalyst.ca, downloaded on 10.03.2018).

\section{Results}

\section{MORPHOLOGICAL AND BIOCHEMICAL CHARACTERIZATION OF SEED QUALITY}

After $24 \mathrm{~h}$ of clinorotation, most of the B. napus seeds germinated, i.e. had clearly visible growing germinal roots. Thereby, at this time point, the seeds germinated under the conditions of simulated microgravity did not show any morphological differences in comparison to

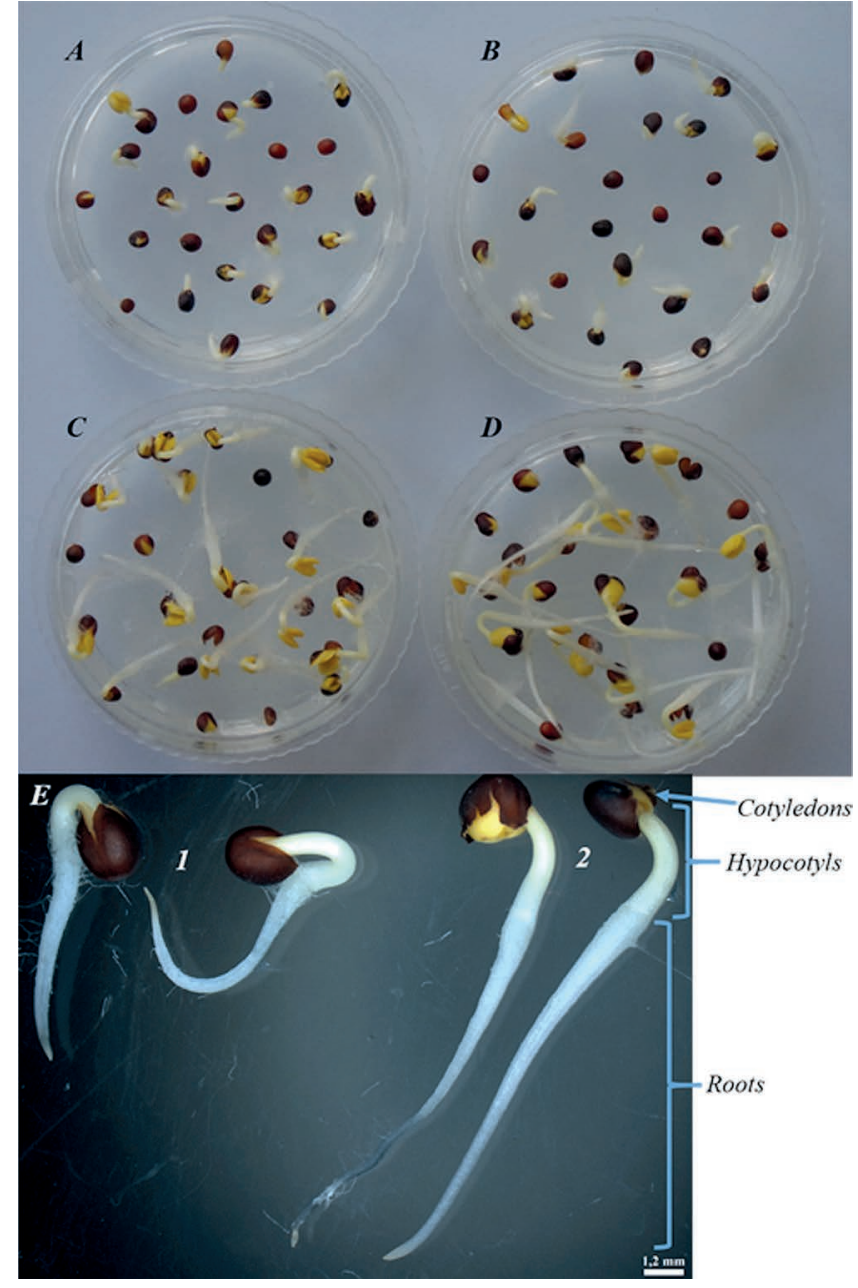

Fig. 1. Oilseed rape seedlings obtained by seed germination for 24 ( $A$, $B)$ and $48(C, D)$ hours on an agarose substrate in the presence of clinorotation $(B, D)$ and under the conditions of static control $(A, C)$. $\mathrm{E}$ - rape seedlings obtained within $48 \mathrm{~h}$ in the absence of (1) and the presence (2) of clinorotation.

the static control (Fig. 1A and B, respectively). However, the further $24 \mathrm{~h}$ of clinorotation were accompanied with essential changes in seedling morphology (Fig. 1C and $\mathrm{D}$ ): the roots of the control seedlings demonstrated growth along the gravity vector, whereas the roots of the clinorotated seedlings developed in different directions. Moreover, the clinorotated seedlings demonstrated increased root length and decreased diameters of elongation and root hair zones in comparison to the static control (Fig. 1E, S-2). Despite this, clinorotation for 24 and 48 hours did not affect the ability of seeds to develop viable seedlings. However, $5 \%$ less normally developed seedlings were observed after $48 \mathrm{~h}$ of clinorotation in comparison to static controls (75 vs $80 \%$, Fig. 2), although this difference was not significant.

At the next step, we addressed the levels of oxidative stress in the tissues of clinorotated germinating seeds in comparison to the corresponding static controls. As can be seen from Fig. 3, the levels of lipid peroxidation (ex- 


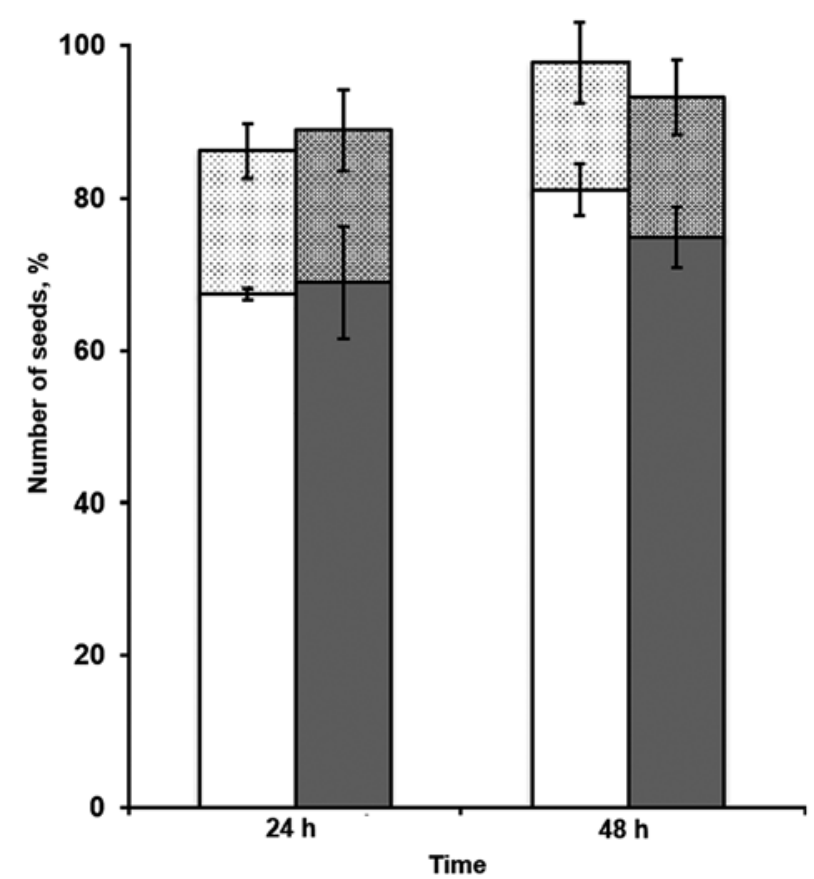

Fig. 2. The ability of the seeds germinating under static conditions (control, white) and in the presence of clinorotation (grey) to form viable seedlings after transfer to static conditions. Normal and abnormal seedlings are marked with filled and rastered columns, respectively. The total number of the seeds used in the experiment was taken as $100 \%$.

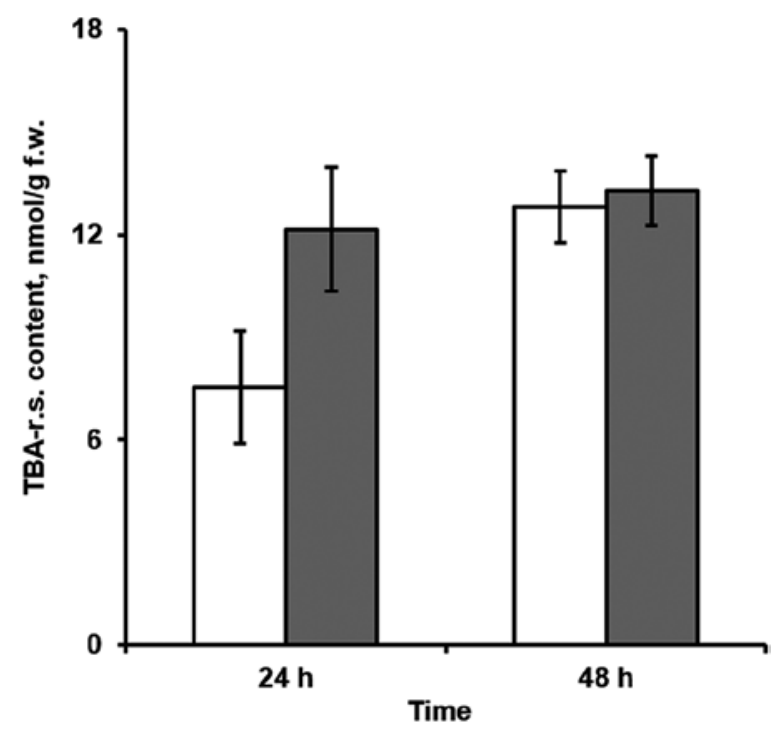

Fig. 3. The content of TBA-reactive substances in the seeds germinating under static conditions (control, white) and in the presence of clinorotation (grey).

pressed as MDA equivalents of TBA-reactive substances) were significantly increased in $48 \mathrm{~h}$-old seedlings (1.7-fold, t-test: $p=0.02$ ) in comparison to the seeds germinated for $24 \mathrm{~h}$. However, although simulated microgravity resulted in a 1.6-fold up-regulation of lipid peroxidation, this difference was not significant (t-test: $p=0.064$ ), whereas no differences were observed one day later (Fig. 3). In- terestingly, control seedlings demonstrated much higher changes in the levels of lipid peroxidation within the second day of the experiment. Thus, during this period, the contents of TBA-reactive substances varied between $12.8 \mathrm{nmol} / \mathrm{g}$ and $13.3 \mathrm{nmol} / \mathrm{g}$ fresh weight (f.w.) in the control and experimental groups, respectively.

The contents of ascorbic (Asc) and dehydroascorbic (DHA) acids, respectively, as well as the total ascorbate contents were not affected by clinorotation (Fig. 4A, B and $\mathrm{C}$, respectively). Thus, after $24 \mathrm{~h}$ of germination, the contents of Asc were 6.65 and $6.35 \mu \mathrm{mol} / \mathrm{g}$ fresh weight in the control and experimental groups, respectively. The next day, Asc was slightly and non-significantly up-regulated in both groups (about $7.5 \mu \mathrm{mol} / \mathrm{g}$ fresh weight). No significant differences in Asc/DHA ratio were observed between time points and treatment groups (Fig. 4D).

\section{EFFECT OF SIMULATED MICROGRAVITY ON PRIMARY SEED METABOLOME}

GC-MS analysis of derivatized dried water-methanolic seedling extracts revealed a total of 75 chromatographic signals (in all four treatment groups), which could be assigned as plant metabolites on the basis of available spectral information (Table S-1). All these prospective metabolites were annotated by EI spectra and $t_{R} s$. Based on spectral similarity and $t_{R}$ with entries of the in-house library and available GMB and NIST libraries, 48 metabolites could be unambiguously identified by coellution with authentic standard (Table 1), whereas the others were annotated as unknowns. The identified metabolites represented di- and tricarboxylic acids (succinic, fumaric, malic, glucaric and citric acids); proteinogenic (alanine, valine, isoleucine, proline, leucine, serine, threonine, methionine, glutamic acid, aspartic acid, asparagine, glutamine, lysine, tyrosine, histidine) and non-proteinogenic (5-oxoproline, 4-hydroxyproline, $\gamma$-aminobutyric acid) amino acids; and carbohydrates (arabinose, xylose, ribose, fructose, sorbose, galactose, mannose, glucose, sucrose, maltose, raffinose, sorbitol, inositol, galactinol, glycerol, glucose-6-phosphate, fructose-6-phosphate) (Table 1). Almost all identified substances were detected in all experimental groups. Only 4-hydroxyproline was unique for one-day-old seedlings, whereas urea was unique for two-day-old control seedlings and $\gamma$-aminobutyric acid was detected only in the plants treated with simulated microgravity for two days.

After conversion of the cdf files in raw format and integration of peak areas at specified $t_{R} s$, quantitative comparisons could be done. The absolute quantification, relying on standard addition and external calibration strategies, revealed sucrose, glucose and malic acid as the major metabolites detected after $24 \mathrm{~h}$ of germination. Their contents in the germinating seeds of the control and clinorotated groups, respectively, were as fol- 
Table 1. Metabolites identified in methanol-water extracts of rape seedlings (Brassica napus L., 24 and $48 \mathrm{~h}$ after planting) in the presence and absence of clinorotation

\begin{tabular}{|c|c|c|}
\hline \multirow{2}{*}{ Metabolite $^{a}$} & \multicolumn{2}{|r|}{ Annotation } \\
\hline & $t_{R}$ & Fragmentation pattern (mass spectra) \\
\hline L-Alanine (2TMS) & 8.95 & 73(26), 116(100), 147(26), 190(8) \\
\hline L-Valine (2TMS) & 12.06 & 73(26), 79(10), 144(100), 147(16), 218(26) \\
\hline Urea (3TMS)* & 12.83 & 73(55), 147(100), 171(55), 189(45), 99(27) \\
\hline Ethanolamine (3TMS) & 13.40 & $73(100), 174(80), 100(40), 86(40)$ \\
\hline Phosphate (3TMS) & 13.60 & 299(100), 73(50), 309(20), 314(20) \\
\hline Glycerine (2TMS) & 13.70 & $59(12), 73(100), 103(32), 117(30), 147(50), 205(40)$ \\
\hline L-Isoleucine (2TMS) & 14.19 & $73(52), 147(12), 158(100), 218(20)$ \\
\hline L-Proline (2TMS) & 14.29 & 142(100), 73(21), 147(15), 216(6), 299(5) \\
\hline L-Glycine (3TMS) & 14.52 & $174(100), 73(50), 147(25), 248(24), 86(15), 276(14)$ \\
\hline L-Leucine (2TMS) & 14.62 & 73(100), 158(70), 102(10), 147(8), 218(5), 232(5) \\
\hline Succinic acid (2TMS) & 14.83 & $72(28), 75(144), 79(10), 147(100), 247(20)$ \\
\hline Glycerinic acid (3TMS) & 15.20 & 73(100), 147(40), 189(30), 205(5), 292(5) \\
\hline Fumaric acid (2TMS) & 15.81 & 73(17), 75(10), 143(14), 147(34), 245(100) \\
\hline L-Serine (3TMS) & 16.02 & $73(32), 100(11), 147(18), 188(10), 204(100), 218(64), 278(10)$ \\
\hline L-Threonine (3TMS) & 16.68 & 73(68), 75(10), 101(18), 117(44), 133(10), 147(28), 203(10), 218(100), 219(90), 291(43) \\
\hline D-Malic acid (3TMS) & 19.35 & $\begin{array}{l}\text { 73(82), 101(10), 133(20), 147(100), 175(14), 189(22), 217(10), 233(58), 245(34), 265(10), } \\
\text { 307(10), 335(16) }\end{array}$ \\
\hline L-Methionine (2TMS) & 20.03 & 73(100), 176(95), 128(36), 147(15), 219(10), 293(8) \\
\hline 5-Oxoproline (2TMS) & 20.07 & 73(260), 147(20), 156(100), 230(14), 232(16), 258(15) \\
\hline L-Aspartic acid (2TMS) & 20.12 & 73(65), 100(11), 116(26), 117(34), 130(36), 147(32), 160(100), 245(15) \\
\hline 4-hydroxyproline* (3TMS) & 20.23 & 73(100), 230(50), 140(23), 147(20), 304(6), 332(6) \\
\hline$y$-aminobutyric acid (3TMS) & 20.32 & 174(100), 73(56), 147(40), 304(24), 216(10), 246(10) \\
\hline L-Glutamic acid (3TMS) & 22.52 & $73(28), 128(17), 147(16), 156(14), 230(12), 246(100), 348(10)$ \\
\hline L-Phenylalanine (2TMS) & 22.58 & 73(60), 100(15), 147(14), 192(62), 218(100) \\
\hline$D$-Xylose (1MEOX) (4TMS) & 23.30 & 73(100), 103(64), 133(11), 147(35), 160(14), 217(47), 307(34) \\
\hline L-Arabinose (1MEOX) (4TMS) & 23.47 & $73(100), 103(68), 133(12), 147(38), 160(12), 189(12), 217(54), 307(36)$ \\
\hline L-Asparagine (3TMS) & 23.63 & 73(100), 231(90), 116(80), 75(45), 132(25), 147(14), \\
\hline$D$-Ribose (1MEOX) (4TMS) & 23.77 & 73(100), 103(69), 133(13), 147(40), 160(15), 189(17), 217(59), 277(10), 307(41) \\
\hline L-Glutamine (3TMS) & 25.94 & 156(100), 73(46), 245(40), 347(12), 203(8) \\
\hline Citric acid (4TMS) & 26.89 & 73(54), 147(58), 211(10), 273(100), 363(280, 347(25), 375(26), 465(15) \\
\hline L-Sorbose (1MEOX) (5TMS) & 28.03 & 73(100), 103(60), 133(12), 147(54), 189(12), 205(13), 217(82), 262(11), 277(13), 307(55) \\
\hline$D$-Fructose (1MEOX) (5TMS) & 28.15 & 73(100), 103(66), 133(14), 147(40), 205(11), 217(53), 277(11), 307(38) \\
\hline D-Galactose (1MEOX) (5TMS) & 28.21 & $\begin{array}{l}\text { 73(99), 103(22), 117(16), 129(14), 133(13), 147(65), 157(12), 160(34), 189(12), 205(71), } \\
\text { 217(44), 229(10), 319(100) }\end{array}$ \\
\hline D-Mannose (1MEOX) (5TMS) & 28.30 & 73(100), 103(17), 117(11), 147(49), 160(28), 205(49), 217(20), 291(5), 319(60) \\
\hline D-Glucose (1 MEOX) (5TMS) & 28.45 & 73(100), 103(19), 117(13), 147(52), 160(32), 205(51), 217(24), 319(62) \\
\hline L-Histidine (3TMS) & 28.9 & 73(80), 154(40), 254(10), 218(5), 238(5) \\
\hline L-Lysine (3TMS) & 29.01 & 73(100), 174(95), 317(91), 318(21), 434(19) \\
\hline
\end{tabular}




\begin{tabular}{|c|c|c|}
\hline D-Sorbitol (6TMS) & 29.20 & 73(100), 103(32), 117(17), 133(10), 147(62), 205(58), 217(46), 307(16), 319(65) \\
\hline L-Tyrosine (2TMS) & 29.33 & 179(100), 73(40), 75(18), 208(18), 219(10), 310(10) \\
\hline Synapic acid (cis-) (2TMS) & 31.6 & 368(100), 338(80), 353(43), 73(45), 323(20) \\
\hline Inositol (6TMS) & 32.17 & $\begin{array}{l}\text { 73(100), 129(17), 133(15), 148(86), 191(40), 204(30), 217(82), 265(20), 291(21), 305(85), } \\
\text { 318(49), 432(14) }\end{array}$ \\
\hline L-Tryptophane (3TMS) & 34.5 & 202(100), 73(75), 291(26), 218(10) \\
\hline Synapic acid (cis-) (2TMS) & 35.60 & 368(100), 338(80), 353(43), 73(45), 323(20) \\
\hline $\begin{array}{l}\text { D-Glucose-6-Phosphate (1 MEOX) } \\
\text { (6TMS) }\end{array}$ & 36.28 & $\begin{array}{l}\text { 73(72), 101(7), 129(13), 133(12), 147(35), 157(8), 160(27), 204(11), 207(6), 211(15), 217(18), } \\
225(7), 299(62), 315(42), 331(16), 341(7), 357(52), 387(100), 471(26)\end{array}$ \\
\hline $\begin{array}{l}\text { D-Fructose-6-Phosphate (1MEOX) } \\
\text { (6TMS) }\end{array}$ & 36.09 & $\begin{array}{l}\text { 73(80), 89(7), 101(7), 103(18), 117(6), 129(17), 133(15), 147(42), 204(6), 207(5), 211(15), } \\
217(63), 225(8), 262(7), 299(62), 315(100), 341(6), 357(40), 373(5), 387(22), 403(15), 459(40)\end{array}$ \\
\hline D-Sucrose (8TMS) & 41.40 & $\begin{array}{l}\text { 73(60), 103(18), 117(6), 129(15), 147(30), 169(12), 217(50), 271(14), 291(6), 361(100), } \\
437(14)\end{array}$ \\
\hline D-Maltose (1MEOX) (8TMS) & 42.81 & $\begin{array}{l}\text { 73(100), 103(20), 117(15), 129(16), 147(54), 160(11), 191(15), 204(67), 217(50), 270(12), } \\
\text { 319(13), 361(98), 480(6) }\end{array}$ \\
\hline Galactinol (9TMS) & 46.60 & $\begin{array}{l}\text { 73(46), 103(12), 129(14), 147(33), 167(6), 191(28), 204(100), 217(44), 305(18), 361(17), } \\
433(14)\end{array}$ \\
\hline$D$-Raffinose (8TMS) & 51.39 & $\begin{array}{l}\text { 73(60), 103(18), 129(24), 133(12), 147(35), 169(15), 189(10), 191(22), 204(47), 207(54), } \\
217(57), 243(14), 271(16), 361(100), 437(24), 451(20)\end{array}$ \\
\hline
\end{tabular}

a Metabolites are represented by the corresponding TMS or MEOX-TMS derivatives; * meanmetabolites, associated with clinorotation
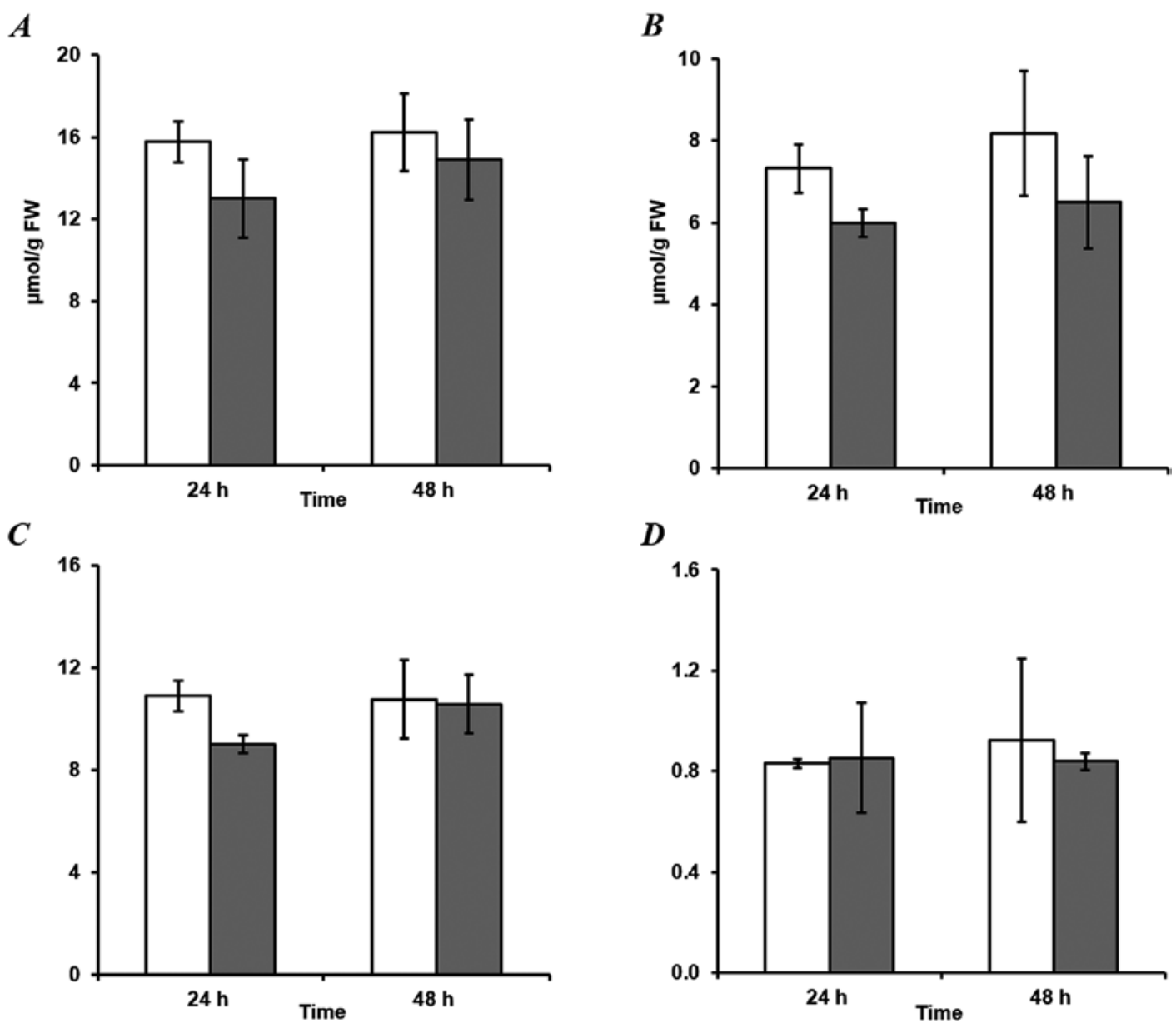

Fig. 4. The contents of total $(A)$, reduced $(B)$ and oxidized ascorbate $(C)$, as well as the ratio of reduced to oxidized ascorbate $(D)$ in seeds germinating under static conditions (white) and during clinorotation (grey). 
Table 2. The content of metabolites in Brassica napus L. seeds germinating for $24 \mathrm{~h}$ and $48 \mathrm{~h}$ in the presence and absence of clinorotation (control)

\begin{tabular}{|c|c|c|c|c|}
\hline \multirow{2}{*}{ Metabolite } & \multicolumn{4}{|c|}{ Content ( $\mu \mathrm{mol} / \mathrm{g}$ fresh weight) } \\
\hline & $24 \mathrm{~h}$ control & 24 hclinorotation & 48 hcontrol & $48 \mathrm{~h}$ clinorotation \\
\hline \multicolumn{5}{|c|}{ Metabolites ( $\geq 100 \mu \mathrm{mol} / \mathrm{g}$ fresh weight), more abundant in one-day-old seedlings } \\
\hline$D$-Sucrose & $2811 \pm 374$ & $1797 \pm 1026$ & $208 \pm 137$ & $73.6 \pm 56.9$ \\
\hline Malic acid & $183 \pm 37$ & $150 \pm 77$ & $38.2 \pm 31.6$ & $21.4 \pm 19.6$ \\
\hline \multicolumn{5}{|c|}{ Metabolites ( $\geq 100 \mu \mathrm{mol} / \mathrm{g}$ fresh weight), more abundant in two-day-old seedlings } \\
\hline$D$-Fructose & $47.2 \pm 18.0$ & $38.0 \pm 12.3$ & $122 \pm 59$ & $140 \pm 59$ \\
\hline D-Glucose & $205 \pm 64$ & $156 \pm 175$ & $658 \pm 409$ & $941 \pm 469$ \\
\hline \multicolumn{5}{|c|}{ Metabolites (from 100 to $1 \mu \mathrm{mol} / \mathrm{g}$ fresh weight), more abundant in one-day-old seedlings } \\
\hline L-Glutamic acid & $79.2 \pm 15.2$ & $66.7 \pm 18.7$ & $25.3 \pm 15.9$ & $16.2 \pm 12.4$ \\
\hline Citric acid & $75.3 \pm 2.0$ & $51.7 \pm 36.6$ & $21.6 \pm 8.8$ & $13.5 \pm 7.5$ \\
\hline L-Aspartic acid & $26.1 \pm 3.1$ & $22.8 \pm 4.2$ & $9.00 \pm 3.88$ & $5.01 \pm 2.48$ \\
\hline L-Alanine & $22.0 \pm 7.3$ & $21.7 \pm 12.4$ & $12.9 \pm 13.5$ & $8.58 \pm 4.08$ \\
\hline$D$-Raffinose & $3.78 \pm 0.82$ & $2.65 \pm 1.29$ & $0.42 \pm 0.29$ & $0.18 \pm 0.05$ \\
\hline$D$-Sorbitol & $1.39 \pm 0.32$ & $1.26 \pm 0.44$ & $0.59 \pm 0.50$ & $0.30 \pm 0.27$ \\
\hline
\end{tabular}

Metabolites (from 100 to $1 \mu \mathrm{mol} / \mathrm{g}$ fresh weight), more abundant in two-day-old seedlings

\begin{tabular}{l|c|c|c|c}
\hline L-Glutamine & $9.01 \pm 1.87$ & $7.87 \pm 1.57$ & $21.3 \pm 9.0$ & $20.5 \pm 5.2$ \\
\hline L-Threonine & $12.7 \pm 2.5$ & $12.1 \pm 0.6$ & $16.1 \pm 8.1$ & $14.2 \pm 6.5$ \\
\hline L-Leucine & $1.89 \pm 0.55$ & $2.21 \pm 0.81$ & $6.98 \pm 5.83$ & $6.61 \pm 3.47$ \\
\hline L-Isoleucine & $3.10 \pm 1.00$ & $4.02 \pm 1.00$ & $9.94 \pm 6.11$ & $8.53 \pm 3.08$ \\
\hline D-Xylose & $1.45 \pm 0.63$ & $1.48 \pm 0.32$ & $2.97 \pm 1.03$ & $3.12 \pm 1.01$ \\
\hline L-Valine & $3.54 \pm 0.75$ & $3.14 \pm 0.54$ & $5.17 \pm 3.18$ & $4.52 \pm 1.74$ \\
\hline L-Serine & $2.95 \pm 0.52$ & $3.23 \pm 0.67$ & $3.86 \pm 2.11$ & $3.69 \pm 1.86$ \\
\hline L-Lysine & $0.96 \pm 0.17$ & $1.27 \pm 0.27$ & $2.57 \pm 1.23$ & $2.32 \pm 0.50$ \\
\hline L-Sorbose & $0.55 \pm 0.28$ & $0.43 \pm 0.22$ & $1.01 \pm 0.80$ & $1.41 \pm 0.51$ \\
\hline
\end{tabular}

Metabolites (from 100 to $1 \mu \mathrm{mol} / \mathrm{g}$ fresh weight), unique for one- or two-day-old seedlings

\begin{tabular}{l|c|c|c|c}
\hline L-Proline & $34.4 \pm 14.3$ & $36.2 \pm 2.1$ & $37.8 \pm 28.4$ & $27.5 \pm 20.1$ \\
\hline Inositol & $11.3 \pm 0.8$ & $9.83 \pm 0.54$ & $10.6 \pm 4.3$ & $8.98 \pm 4.18$ \\
\hline L-Asparagine & $18.9 \pm 3.7$ & $14.1 \pm 6.0$ & $14.8 \pm 6.6$ & $10.9 \pm 3.1$ \\
\hline L-Methionine & $2.70 \pm 1.05$ & $3.57 \pm 1.29$ & $3.36 \pm 1.59$ & $3.30 \pm 1.53$ \\
\hline Glycine & $2.20 \pm 0.88$ & $1.74 \pm 0.73$ & $2.49 \pm 1.78$ & $2.50 \pm 0.77$ \\
\hline D-Galactose & $1.46 \pm 0.27$ & $1.40 \pm 0.26$ & $1.58 \pm 0.88$ & $1.91 \pm 0.87$ \\
\hline Succinic acid & $1.19 \pm 0.12$ & $1.03 \pm 0.03$ & $1.25 \pm 0.66$ & $1.22 \pm 0.30$ \\
\hline Fumaric acid & $2.02 \pm 0.65$ & $1.86 \pm 0.72$ & $1.21 \pm 1.03$ & $1.24 \pm 0.66$ \\
\hline Glycerine & $1.91 \pm 0.58$ & $1.52 \pm 0.17$ & $1.79 \pm 1.15$ & $2.09 \pm 0.56$ \\
\hline
\end{tabular}

Minor metabolites ( $\leq 1 \mu \mathrm{mol} / \mathrm{g}$ fresh weight), unique for one- or two-day-old seedlings

\begin{tabular}{l|c|c|c|c}
\hline$D$-Maltose & $0.66 \pm 0.13$ & - & $0.78 \pm 0.34$ & $0.48 \pm 0.11$ \\
\hline$D$-Glucaricacid & $0.26 \pm 0.12$ & $0.22 \pm 0.08$ & $0.13 \pm 0.05$ & $0.095 \pm 0.08$ \\
\hline$D$-Mannose & $0.16 \pm 0.09$ & $0.25 \pm 0.12$ & $0.42 \pm 0.21$ & $0.29 \pm 0.11$ \\
\hline$D$-Arabinose & $0.05 \pm 0.03$ & - & $0.15 \pm 0.10$ & $0.16 \pm 0.03$ \\
\hline$D$-Ribose & $0.20 \pm 0.06$ & - & $0.21 \pm 0.14$ & $0.28 \pm 0.14$ \\
\hline
\end{tabular}

All numbers are presented as average of 2-3 replicates. A dash (-) indicates the absence of a metabolite in the samples. 


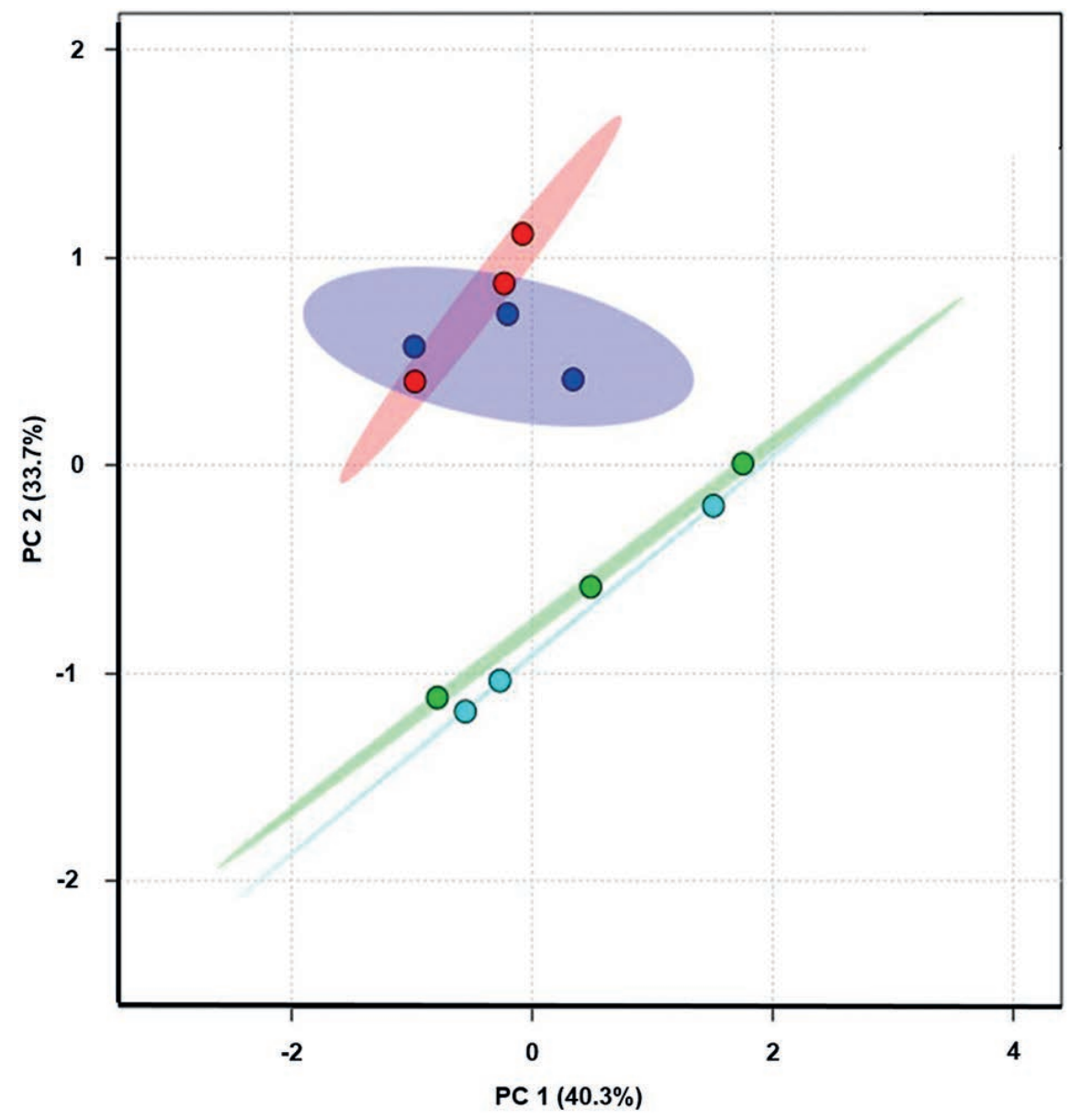

Fig. 5. Principal component analysis (PCA) of metabolites patterns, acquired with the oilseed rape seedlings germinated for 24 and $48 \mathrm{~h}$ in the presence or absence of clinorotation. $24 \mathrm{~h}$ : red - control, dark blue - clinorotation; 48 h: green - control, light-blue - clinorotation. PCA was done with MetaboAnalyst 4.0 (http://www.metaboanalyst.ca/).

lows: sucrose -2.8 and $1.8 \mathrm{mmol} / \mathrm{g}$ f.w; malic acid 0.18 and $0.15 \mathrm{mmol} / \mathrm{g}$ f.w., whereas glucose accounted for $0.2 \mathrm{mmol} / \mathrm{g}$ f.w. within both experimental groups. In the two-day-old seedlings, the contents of glucose and fructose were increased 3.5 - and 2.5 -fold, respectively, in comparison to those of the one-day-old germinating seeds. On the other hand, the same comparisons for sucrose and malic acid revealed 13- and 4-fold decreases, respectively. Several other carbohydrates, identified in one- and two-day-old seedlings, such as mannose, ribose and arabinose, were found at 50-420 nmol/g f.w. and could be designated as low-abundant metabolites. However, the absolute quantification analysis revealed no statistically significant clinorotation-related alterations in contents of individual metabolites in both age groups (Table 2). Similar information was obtained by the principal component analysis (PCA) applied to the metabolite patterns of germinating seeds. Thus, PCA indicated clear differences in the metabolite profiles of seeds germinated for 24 and $48 \mathrm{~h}$. In this context, the variability of individual metabolite intensities could be explained by the principal component 2 (PC 2, Fig. 5). On the other hand, the metabolome variability related to $3 \mathrm{D}$-clinorotation could not be clearly observed in the PCA score plots (Fig. 5).

The same metabolite patterns of germinating seeds were also addressed by relative quantification, based on the intensity of specific extracted ion chromatograms (XICs). Thereby, the pair comparisons (t-test at the confidence level of $p<0.05$ ) of integrated peak areas obtained for individual metabolites (Supplementary information, Tables S1 and S2) revealed only one regulated metabolite, namely, glucose-6-phosphate, the content of which was significantly decreased after clinorotation of seeds during the first $24 \mathrm{~h}$ of their germination.

In general, the limited numbers of significantly regulated metabolites revealed by the analysis of the seeds germinating under clinorotation and static conditions could be related to high biological dispersion in both the control and experimental groups. To decrease the impact of this biological dispersion and to highlight the metabolites whose contents were affected 

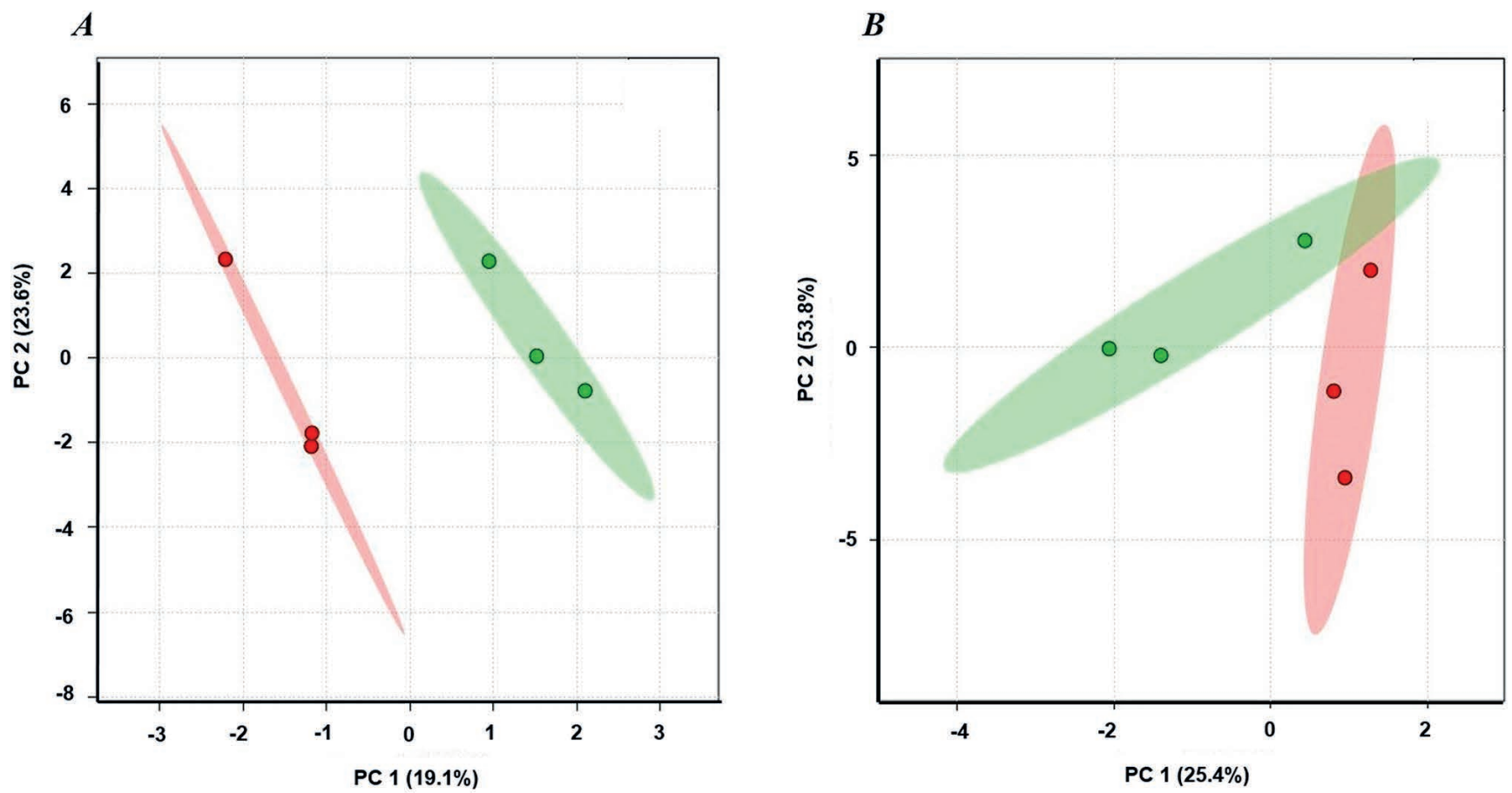

Fig. 6. Score plots built for the first two principal components (PC) derived from partial least squares discriminant analysis (PLS-DA) of the metabolites concentrations in rape seedlings after 24 (A) and 48 (B) hours of clinorotation (green) and static conditions (control, red). PLS-DA was done with MetaboAnalyst 4.0 (http://www.metaboanalyst.ca/).

by $3 \mathrm{D}$-clinoratation, the metabolite patterns were subjected to partial least squares discriminant analysis (PLS-DA, Fig. 6). This analysis revealed clearly distinct clusters of the individual replicates, representing control and clinorotated groups in two-dimensional score plots built for two principal components explaining in total $\sim 43 \%$ and $\sim 79 \%$ of the overall variance for seeds germinating for $24 \mathrm{~h}$ (Fig. 6, A) and $48 \mathrm{~h}$ (Fig. 6, B), respectively. For both age groups the metabolite dynamics related to $3 \mathrm{D}$-clinorotation were mainly reflected in score values of principle component 1 (PC1). The top ten metabolites (i. e. the major loadings) with the highest impact on the two principal components are presented in Figure 7. These compounds, most strongly contributing to $\mathrm{PC} 1$, and therefore related to the observed relative quantitative differences in metabolite patterns caused by 3D-clinorotation, are mostly different sugars (sucrose, galactose, mannose), amino acids (5-oxoproline, pyroglutamic acid, methionine, histidine, phenylalanine), and the players of lipid metabolism pathways (glycerol, 1-monopalmitate glycerol, 2-monostearate glycerol, stearic acid), as well as synapic acid.

\section{Discussion}

Although the effects of both real and simulated microgravity have been intensively studied during the last decade (Matía et al., 2009; Matía et al., 2010; Morita, 2010; Paul et al., 2013; De Micco et al., 2014), the research has been mostly focused on genomic and transcriptomics approaches (Paul et al., 2013; Zupanska et al., 2013). Other methods of functional genomics, i.e. proteomics and metabolomics, are rarely employed, and are usually applied to relatively simple systems, like cell or tissue cultures (Barjaktarović et al., 2007; Barjaktarović et al., 2009). On the other hand, not all steps of plant ontogenesis are equally well characterized in respect to microgravity-related effects. Most of the available data were collected for mature plants, whereas the effects of simulated microgravity on seed germination and development of seedlings had been addressed to a much lesser extent. Thus, here we address the effect of 3Dclinorotation on seed germination as the stage of plant ontogenesis most sensitive to abiotic and biotic stressors (Kranner et al., 2010; Watt and Bloomberg, 2012; Nee, Xiang and Soppe, 2017). We consider here the simulated microgravity-related effects on the seed primary metabolome in parallel to the accompanying physiological and biochemical changes, and discuss it in the context of the alterations in the B. napus seed proteome, recently characterized in the same samples (Frolov et al., 2018).

The fact that clinorotation did not affect the early steps of seedling development (i.e. no effect on the germination rates or seed morphology was observed, Fig. 2) might indicate low levels of stress induced in germinating seeds by simulated microgravity. To address the severity of oxidative stress in soluble compartments of seedling cells, we quantified the levels of ascorbic acid 

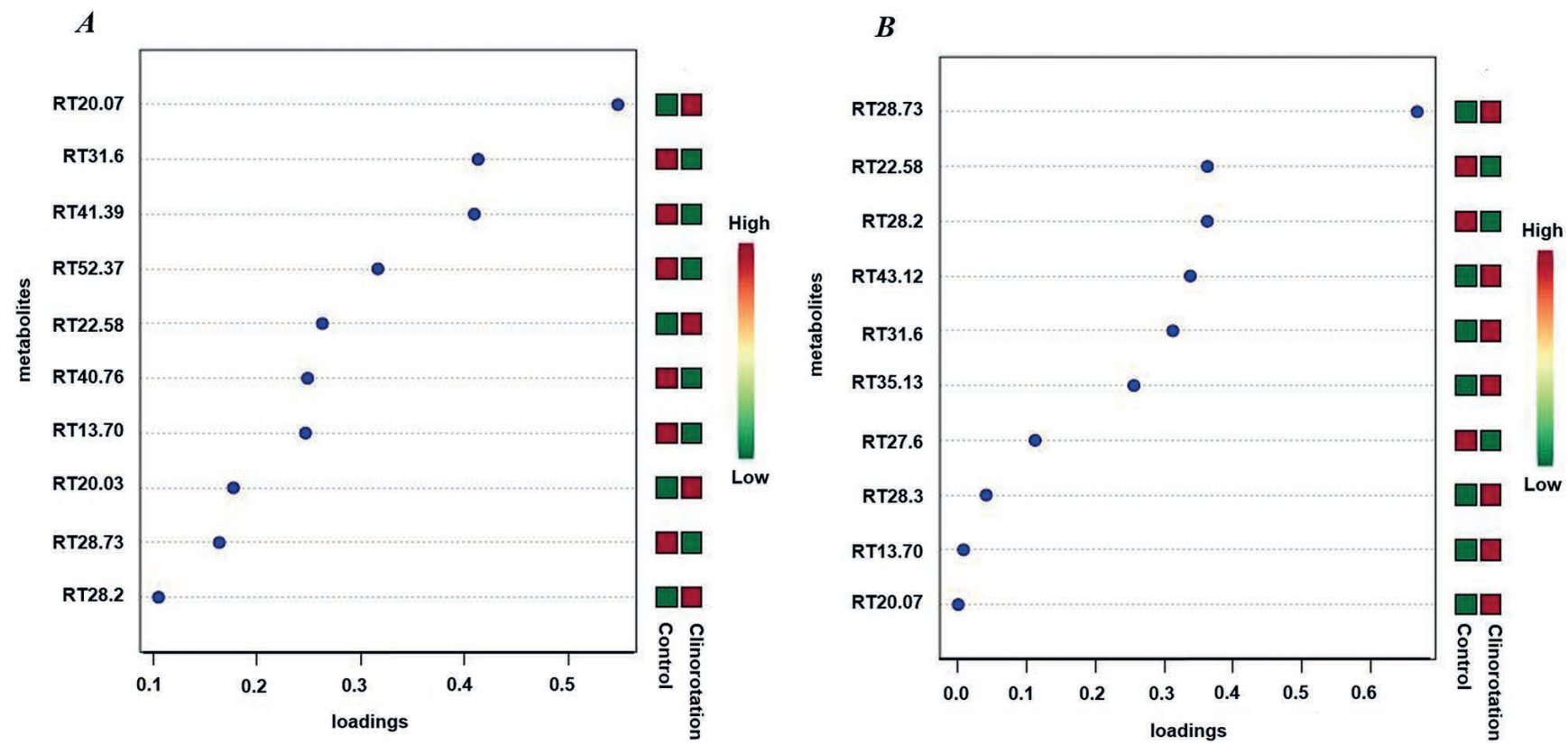

Fig. 7. PLS-DA loadings plots built for metabolite patterns obtained after 24 (A) and 48 (B) hours of germination in the presence and absence of clinorotation. Ten metabolites for each time point, predominantly contributing to the PLS-DA model, were plotted for the PC1, explaining the main differences between the control and clinorotation variants. PLS-DA was done with MetaboAnalyst 4.0 (http://www.metaboanalyst.ca/) The metabolites were encoded as follows: RT20.7 - pyroglutamic acid; RT31.6 - synapic acid; RT41.39 — sucrose; RT52.37 - unknown oligosaccharide; RT22.58 - phenylalanine; RT40.76 - 1-monopalmitat-glycerol; RT13.70 - glycerin; RT20.03 - methionine; RT28.73 - galactose (Peak 2); RT28.2 - mannose; RT43.12 - 2-monostearate-glycerol; RT35.13 - stearic acid; RT27.6 - unknown; RT28.3 - galactose (Peak 1).

and dehydroascorbate - the major water-soluble antioxidant in plants. These experiments showed the absence of changes in the Asc/DHA ratios and contents of individual forms of ascorbate (Fig. 4). Indeed, as can be judged by the changes in the contents of lipid peroxidation products in the presence of simulated microgravity (Fig. 3), clinorotation resulted in minimal oxidative stress in germinating seeds during the time of observation. On the other hand, the morphological alterations that we observed in two-day-old seedlings (Fig. 1), i.e. changes in length and thickness of roots, were earlier described by Matia et al. (2009). This might indicate adaptation to the simulated microgravity conditions, and indirectly confirm development of stress response in seedlings. This accelerated growth of seedling roots might be underlied by enhanced proliferation of cells in root apical meristem (Matia et al., 2010). Thereby, direction of root growth is determined at the moment of seed coat penetration during the germination process (Tairbekov, 1997).

Analysis of clinorotation-related changes in the profiles of hydrophilic primary metabolites revealed 1.5-fold down-regulation of glucose-6-phosphate (Table S-1). This metabolite can be a substrate of phosphoglucomutase, which was 16-fold up-regulated during the first $24 \mathrm{~h}$ of clinorotation (Frolov et al., 2018). This enzyme plays an important role in regulation of the fluxes of phosphorylated sugars between different cell processes, like synthesis and degradation of sucrose and starch (Malinova et al., 2014). This enzyme is involved in energy metabolism, and its up-regulation under microgravity conditions is in agreement with published data (Aubry-Hivet et al., 2014), also indicating involvement of phosphoglucomutase in gravity perception (Thieme et al., 2015). Indeed, it was an important contributor in the total difference observed between the groups (Fig. 7). Also, this enzyme is involved in the catabolism of galactose, whose regulation under 3D-clinorotation was confirmed by PLS-DA. On the other hand, the levels of galactose contents may also be dependent on the increase of several $\beta$-galactosidase activities involved in remodeling of the cell wall (Frolov et al., 2018; MoneoSánchez et al., 2018).

Another group of metabolites demonstrating dynamics associated with clinorotation for $24 \mathrm{~h}$ and $48 \mathrm{~h}$ (as was confirmed by PLS-DA) was represented by compounds involved in lipid metabolism, such as glycerol, stearic acid and lysolipids (2-monostearate glycerol and 1-monopalmitate glycerol, Fig. 7, Tables S-1 and S-2). Catabolism of storage lipids via the glyoxylate cycle with a subsequent conversion into sugars is characteristic for germination of seeds rich with oil storage substances, such as seeds of oilseed rape. Clinorotation-induced alternations in the levels of the lipid-related metabolites might indicate sensitivity of lipid catabolism to simulated microgravity. This is also in agreement with proteomic data which demonstrated a clinorotationinduced increase in synthesis of acyl-CoA oxidase 2, 
an enzyme of fatty acid beta-oxidation in peroxisomes and glyoxysomes, enhanced levels of peroxisomal citrate synthase, cytoplasmic NADP-malic enzyme, and phosphoenolpyruvate carboxykinase (Frolov et al., 2018).

Remarkably, the levels of methionine in one-dayold germinating seeds demonstrated a clear clinorotation-related dynamic. In the corresponding proteomic dataset, clinorotation induced an essential increase in contents of S-adenosyl-L-methionine-dependent methyltransferases (Frolov et al., 2018). Methionine is a direct precursor of S-adenosyl-L-methionine, which is, in turn, a principal methyl donor for methylation reactions involving sulfur atom and plays a key role in the transfer of methyl groups to various biomolecules, including proteins, DNA and secondary metabolites (Moffatt and Weretilnyk, 2002). Importantly, the SAM-dependent transmethylation, methionine can also be involved in synthesis of the hormone ethylene. Besides methionine, several other amino acids such as phenylalanine and 5-oxoproline were also responsive to $3 \mathrm{D}$-clinorotation. In general, their levels can reflect alternations occurring in protein metabolism. Thus, pyroglutamic acid is a product of glutathione degradation. On the other hand, it could be a metabolite of glutamic acid. Pyroglutamic acid often can be found as a post-translational modification of N-terminal glutamate as a result of glutaminylcylase reaction (Kumar and Bachhawat, 2012). Increased activity of aminopeptidases (Kumar and Bachhawat, 2012; Frolov et al., 2018) under 3D-clinorotation might be partly linked to the altered pyroglutamic acid level.

In general, the study of the metabolite patterns associated with clinorotation revealed a high dispersion of the individual metabolite abundances between biological replicates. This could be observed both for experimental and control seedlings at 24 - and 48 -h time points. This might indicate high metabolome plasticity and lability, characteristic for germinating seeds. Moreover, genotype-specific response of germinating seeds to simulated microgravity might impact this variability, clearly observed here.

\section{Conclusion}

Gravity is one of the major factors affecting plants, defining the direction of their growth, symmetry of organs and coordinating a plethora of physiological processes. Although the transcriptome and proteome of germinating seeds are relatively well characterized, microgravityrelated changes in the plant metabolome still require further studies. However, analysis of clinorotation-related changes in the metabolome of developing seedlings is even more challenging in comparison to corresponding proteomics or transcriptomics surveys. The major reason for this is the high liability of the seed metabolome and a large variability in response of individual seeds and seedlings to microgravity stimuli. Because of this, the corresponding datasets suffer from a high dispersion of abundances detected for individual analytes. This results in lower confidence of the obtained clinorotation-related differences. Therefore, higher numbers of biological replicates and ideally several replicated metabolomics experiments need to be performed.

\section{Acknowledgements}

The authors thank the Russian Foundation for Basic Research (project 17-04-00862) and Saint Petersburg State University (grant № 7398/1, appendix № 3, decision from 24.07.2018) for the financial support. The Research Resource Centers for Molecular and Cell Technologies of Saint Petersburg State University are acknowledged for technical support.

\section{References}

Aubry-Hivet, D., Nziengui, H., Rapp, K., Oliveira, O., Paponov, I. A., Li, Y., Hauslage, J., Vagt, N., Braun, M., Ditengou, F. A., Dovzhenko, A., and Palme, K. 2014. Analysis of gene expression during parabolic flights reveals distinct early gravity responses in Arabidopsis roots. Plant Biology 16:129-141. https://doi.org/10.1111/plb.12130

Barjaktarović, Ž., Babbick, M., Nordheim, A., Lamkemeyer, T., Magel, E., and Hampp, R. 2009. Alterations in protein expression of Arabidopsis thaliana cell cultures during hyper- and simulated micro-gravity. Microgravity Science and Technology 21:191-196. https://doi.org/10.1007/ s12217-008-9058-8

Barjaktarović, Ž., Nordheim, A., Lamkemeyer, T., Fladerer, C., Madlung, J., and Hampp, R. 2007. Time-course of changes in amounts of specific proteins upon exposure to hyper-g, 2-D clinorotation, and 3-D random positioning of Arabidopsis cell cultures. Journal of Experimental Botany 58:4357-4363. https://doi.org/10.1093/jxb/erm302

Benjamini, Y. and Hochberg, Y. 1995. Controlling the false discovery rate: A practical and powerful approach to multiple testing. Journal of the Royal Statistical Society. Series $B$ (Methodological) 57(1):289-300.

Bilova, T., Lukasheva, E., Brauch, D., Greifenhagen, U., Paudel, G., Tarakhovskaya, E., Frolova, N., Mittasch, J., Balcke, G. U., Tissier, A., Osmolovskaya, N., Vogt, T., Wessjohann, L. A., Birkemeyer, C., Milkowski, C., and FroIov, A. 2016. A snapshot of the plant glycated proteome: structural, functional and mechanistic aspects. The Journal of Biological Chemistry 291(14):7621-36. https://doi. org/10.1074/jbc.M115.678581

Bilova, T., Paudel, G., Shilyaev, N., Schmidt, R., Brauch, D., Tarakhovskaya, E., Milrud, S., Smolikova, G, Tissier, A., Vogt, T., Sinz, A., Brandt, W., Birkemeyer, C., Wessjohann, L. A., and Frolov, A. 2017. Global proteomic analysis of advanced glycation end products in the Arabidopsis proteome provides evidence for age-related glycation hot spots. The Journal of Biological Chemistry 292(38):15758-15776. https://doi.org/10.1074/jbc.M117.794537

Borst, A. G. and van Loon, J.J.W. A. 2009. Technology and developments for the random positioning machine, RPM. Microgravity Science and Technology 21:287-292. https://doi.org/10.1007/s12217-008-9043-2

Correll, M.J., Pyle, T.P., Millar, K. D., Sun, Y., Yao, J., Edelmann, R. E., and Kiss, J. Z. 2013. Transcriptome analyses of Arabidopsis thaliana seedlings grown in space: implications for gravity-responsive genes. Planta 238:519-533. https://doi.org/10.1007/s00425-013-1909-x 
De Micco, V., De, P. S., Paradiso, R., and Aronne, G. 2014. Microgravity effects on different stages of higher plant life cycle and completion of the seed-to-seed cycle. Plant Biology 16(s1):31-38. https://doi.org/10.1111/plb.12098

Dubinin, N. P. and Vaulina, E. N. 1976. The evolutionary role of gravity. Life Sciences and Space Research 14:47-55.

Frolov, A., Bilova, T., Paudel, G., Berger, R., Balcke, G. U., Birkemeyer, C., and Wessjohann, L. A. 2017. Early responses of mature Arabidopsis thaliana plants to reduced water potential in the agar-based polyethylene glycol infusion drought model. Journal of Plant Physiology 208:70-83. https://doi.org/10.1016/j.jplph.2016.09.013

Frolov, A., Didio, A., Ihling, C., Chantzeva, V., Grishina, T., Hoehenwarter, W., Sinz, A., Smolikova, G., Bilova, T., and Medvedev, S. 2018. The effect of simulated microgravity on Brassica napus seedling proteome. Functional Plant Biology 45(4):440-452. https://doi.org/10.1071/FP16378

Herranz, R., Anken, R., Boonstra, J., Braun, M., Christianen, P. C., de Geest, M., Hauslage, J., Hilbig, R., Hill, R. J., Lebert, M., Medina, F. J., Vagt, N., Ullrich, O., van Loon, J. J, and Hemmersbach, R. 2013. Ground-based facilities for simulation of microgravity: organism-specific recommendations for their use, and recommended terminology. Astrobiology 13:1-17. https://doi.org/10.1089/ast.2012.0876

Hoson, T., Soga, K., Wakabayashi, K., Hashimoto, T., Karahara, I., Yano, S., Tanigaki, F., Shimazu, T., Kasahara, H., Masuda, D., and Kamisaka, S. 2014. Growth stimulation in inflorescences of an Arabidopsis tubulin mutant under microgravity conditions in space. Plant Biology 16:91-96. https://doi.org/10.1111/plb.12099

Inglis, P.W., Ciampi, A. Y., Salomao, A. N., Costa, T. S., and Azevedo, V. C. 2014. Expression of stress-related genes in zebrawood (Astronium fraxinifolium, Anacardiaceae) seedlings following germination in microgravity. Genetics and Molecular Biology 37:81-92. https://doi.org/10.1590/ S1415-47572014000100014

ISTA, 2003. International Seed Testing Association, ISTA Handbook on Seedling Evaluation, 3rd ed. ISBN 3-906549-39-9

Jagtap, S. S., Awhad, R. B., Santosh, B., and Vidyasagar, P. B. 2011. Effects of clinorotation on growth and chlorophyll content of rice seeds. Microgravity Science and Technology 23:41-48. https://doi.org/10.1007/s12217-010-9222-9

Jeong, K., Kim, S., and Bandeira, N. 2012. False discovery rates in spectral identification. BMC Bioinformatics 13(Suppl 16):S2. https://doi.org/10.1186/1471-2105-13-S16-S2

Kolesnikov, Y.S., Kretynin, S. V., Volotovsky, I.D., Kordyum, E. L., Ruell, E., and Kravetset, V.S. 2016. Molecular mechanisms of gravity perception and signal transduction in plants. Protoplasma 253:987. https://doi. org/10.1007/s00709-015-0859-5

Kordyum, E. L. 1997. Biology of plant cells in microgravity and under clinostating. International Review of Cytology 171:178. https://doi.org/10.1016/S0074-7696(08)62585-1

Kordyum, E. L. 2014. Plant cell gravisensitivity and adaptation to microgravity. Plant Biology 1:79-90. https://doi. org/10.1111/plb.12047

Kranner, I., Minibayeva, F. V., Beckett, R.P., and Seal, C. E. 2010. What is stress? Concepts, definitions and applications in seed science. New Phytologist 188:655-673. https://doi.org/10.1111/j.1469-8137.2010.03461.x

Krishnamurthy, A., Ferl, R. J., and Paul, A.-L. 2018. Comparing RNA-Seq and microarray gene expression data in two zones of the Arabidopsis root apex relevant to spaceflight. Applications in Plant Sciences 6(11):e1197. https:// doi.org/10.1002/aps3.1197

Kumar, A. S. and Bachhawat, A. K. 2012. Pyroglutamic acid: throwing light on a lightly studied metabolite. Current Science 102(2):288-297.
Malinova, I., Kunz, H.-H., Alseekh, S., Herbst, K., Fernie, A. R., Gierth, M., and Fettke, J. 2014. Reduction of the cytosolic phosphoglucomutase in Arabidopsis reveals impact on plant growth, seed and root development, and carbohydrate partitioning. PLOS ONE 9(11):e112468. https://doi. org/10.1371/journal.pone.0112468

Manzano, A. I., Matía, I., González-Camacho, F., CarneroDíaz, E., Van Loon, J.J. W. A, Dijkstra, C., Larkin, O., Anthony, P., Davey, M. R., Marco, R., and Medina, F. J. 2009. Germination of Arabidopsis seed in space and in simulated microgravity: alterations in root cell growth and proliferation. Microgravity Science and Technology 21(4):293297. https://doi.org/10.1007/s12217-008-9099-z

Matía, I., González-Camacho, F., Herranz, R., Kiss, J. Z., Gasset, G., van Loon, J.J.W. A., Marco, R., and Medina, F.J. 2010. Plant cell proliferation and growth are altered by microgravity conditions in spaceflight. Journal of Plant Physiology 167(3):184-193. https://doi.org/10.1016/j. jplph.2009.08.012

Matía, I., van Loon, J.J.W. A., Carnero-Díaz, E., Marco, R., and Medina, F.J. 2009. Seed germination and seedling growth under simulated microgravity causes alterations in plant cell proliferation and ribosome bio-genesis. $\mathrm{Mi}$ crogravity Science and Technology 21:169-174 https://doi. org/10.1007/s12217-008-9069-5

Mazars, C., Briere, C., Grat, S., Pichereaux, C., Rossignol, M., Pereda-Loth, V., Eche, B., Boucheron-Dubuisson, E., Le, D. I., Medina, F. J., Graziana, A., and Carnero-Diaz, E. 2014. Microgravity induces changes in microsome-associated proteins of Arabidopsis seedlings grown on board the international space station. Plant Signaling \& Behavior 9:e29637. https://doi.org/10.4161/psb.29637

Medina, F. J. and Herranz, R. 2010. Microgravity environment uncouples cell growth and cell proliferation in root meristematic cells: the mediator role of auxin. Plant Signaling \& Behavior 5(2):176-179. https://doi.org/10.4161/psb.5.2.10966

Medvedev, S. S. 2012. Mechanisms and physiological role of polarity in plants. Russian Journal of Plant Physiology 59:502514. https://doi.org/10.1134/S1021443712040085

Medvedev, S. S. 2018. Principles of calcium signal generation and transduction in plant cells. Russian Journal of Plant Physiology 65:771-783. https://doi:10.1134/ S1021443718060109

Milkovska-Stamenova, S., Schmidt, R., Frolov, A., and Birkemeyer, C. 2015. GC-MS method for the quantitation of carbohydrate intermediates in glycation systems. Journal of Agricultural and Food Chemistry 63:5911-5919. https://doi.org/10.1021/jf505757m

Moffatt, B.A. and Weretilnyk, E. A. 2002. Sustaining S-adenosyl-I-methionine-dependent methyltransferase activity in plant cells. Physiologia Plantarum 113(4):435-442. https://doi.org/10.1034/j.1399-3054.2001.1130401.x

Moneo-Sánchez, M., Izquierdo, L., Martín, I., HernándezNistal, J., Albornos, L., Dopico, B., and Labrador, E. 2018. Knockout mutants of Arabidopsis thaliana $\beta$-galactosidase. Modifications in the cell wall saccharides and enzymatic activities. Biologia Plantarum 62:8088. https://doi.org/10.1007/s10535-017-0739-2

Morita, M. T. 2010. Directional gravity sensing in gravitropism. Annual Review of Plant Biology 61:705-720. https:// doi.org/10.1146/annurev.arplant.043008.092042

Nee, G., Xiang, Y., and Soppe, W.J.J. 2017. The release of dormancy, a wake-up call for seeds to germinate. Current Opinion in Plant Biology 35:8-14. https://doi. org/10.1016/j.pbi.2016.09.002

Paudel, G., Bilova, T., Schmidt, R., Greifenhagen, U., Berger, R., Tarakhovskaya, E., Stöckhardt, S., Balcke, G. U., Humbeck, K., Brandt, W., Sinz, A., Vogt, T., Birkemeyer, C., 
Wessjohann, L., and Frolov, A. 2016. Changes in Arabidopsis thaliana advanced glycated proteome induced by the polyethylene glycol-related osmotic stress. Journal of Experimental Botany 67(22):6283-6295. https://doi. org/10.1093/jxb/erw395

Paul, A. L., Zupanska, A. K., Ostrow, D. T., Zhang, Y., Sun, Y., Li, J. L., Shanker, S., Farmerie, W. G., Amalfitano, C. E., and Ferl, R.J. 2012. Spaceflight transcriptomes: unique responses to a novel environment. Astrobiology 12:40-56. https://doi.org/10.1089/ast.2011.0696

Paul, A. L., Zupanska, A. K., Schultz, E. R., and Ferl, R. J. 2013. Organ-specific remodeling of the Arabidopsis transcriptome in response to spaceflight. BMC Plant Biology 13:112. https://doi.org/10.1186/1471-2229-13-112

Paul, A. L., Wheeler, R. M., Levine, H. G., and Ferl, R. J. 2013. Fundamental plant biology enabled by the space shuttle. American Journal of Botany 100:226-234. https://doi. org/10.3732/ajb.1200338

Popova, A. and Ivanenko, G. 2010. Structural and cytochemical aspects of Brassica rapa L. embryogenesis under clinorotation. Cytology and Genetics 44(2):88-94. https:// doi.org/10.3103/S0095452710020039

Popova, A., Musgrave, M., and Kuang, A. 2009. The development of embryos in Brassica rapa L. in microgravity. Cytology and Genetics 43(2):89-93. https://doi.org/10.3103/ S0095452709020030

Pozhvanov, G.A., Klimenko, N.S., Bilova, T.E., Medvedev, S. S., and Shavarda, A. L. 2017. Ethylene-dependent adjustment of metabolite profiles in Arabidopsis thaliana seedlings during gravitropic response. Russian Journal of Plant Physiology 64(6):906-918. https://doi.org/10.7868/ S0015330317050098

Sato, E. M., Hijazi, H., Bennett, M. J., Vissenberg, K., and Swarup, R. 2015. New insights into root gravitropic signaling. Journal of Experimental Botany 66(8):2155-2165. https:// doi.org/10.1093/jxb/eru515

Sychev, V. N., Levinskikh, M.A., Gostimsky, S. A., Bingham, G. E., and Podolsky, I. G. 2007. Spaceflight effects on consecutive generations of peas grown on board the Russian segment of the International Space Station. Acta Astronautica 60:426-432. https://doi.org/10.1016/j.actaastro.2006.09.009

Tairbekov, M. G. 1997. Gravitazionnaya biologia kletki (teoria i experiment) [Gravitational biology of the cell (the theory and experiment)]. Moscow: Institute of Med.-Bio. Problems 124 pp.
Thieme, C.J., Rojas-Triana, M., Stecyk, E., Schudoma, C., Zhang, W., Yang, L., Miñambres, M., Walther, D., Schulze, W. X., Paz-Ares, J., Scheible, W. R., and Kragler, F. 2015. Endogenous Arabidopsis messenger RNAs transported to distant tissues. Nature Plants 1(4):15025. https://doi. org/10.1038/nplants.2015.25

van Loon, J. J. W. A. 2007. Some history and use of the random positioning machine, RPM, in gravity related research. Advances in Space Research 39:1161-1165. https://doi. org/10.1016/j.asr.2007.02.016

Vandenbrink, J.P. and Kiss, J.Z. 2016. Space, the final frontier: A critical review of recent experiments performed in microgravity. Plant Science 243:115-119. https://doi. org/10.1016/j.plantsci.2015.11.004

Wang, H., Li, X., Krause, L., Görög, M., Schüler, O., Hauslage, J., Hemmersbach, R., Kircher, S., Lasok, H., Haser, T., Rapp, K., Schmidt, J., Yu, X., Pasternak, T., Aubry-Hivet, D., Tietz, O., Dovzhenko, A., Palme, K., and Ditengou, F. A. 2016. 2-D clinostat for simulated microgravity experiments with Arabidopsis seedlings. Microgravity Science and Technology 28(1):59-66. https://doi.org/10.1007/ s12217-015-9478-1

Watt, M. S. and Bloomberg, M. 2012. Key features of the seed germination response to high temperatures. New Phytologist 196:332-336. https://doi.org/10.1111/j.14698137.2012.04280.x

Wie, N., Tan, C., Qi, B., Zhang, Y., Xu, G., and Zheng, H. 2010. Changes in gravitational forces induce the modification of Arabidopsis thaliana silique pedicel positioning. Journal of Experimental Botany 61:3875-3884. https://doi. org/10.1093/jxb/erq200

Wolverton, C. and Kiss, J. Z. 2009. Gravitational and space biology. An update on plant space biology. Gravitational and Space Biology 22(2):1-20.

Wyatt, S. E. and Kiss, J. Z. 2013. Plant tropisms: from Darwin to the International Space Station. American Journal of Botany 100(1):1-3. https://doi.org/10.3732/ajb.1200591

Zheng, H. Q., Han, F., and Le, J. 2015. Higher plants in space: microgravity perception, response, and adaptation. Microgravity Science and Technology 27(6):377-386. https:// doi.org/10.1007/s12217-015-9428-y

Zupanska, A. K., Denison, F. C., Ferl, R. J., and Paul, A. L. 2013. Spaceflight engages heat shock protein and other molecular chaperone genes in tissue culture cells of Arabidopsis thaliana. American Journal of Botany 100(1):235248. https://doi.org/10.3732/ajb.1200343 


\section{SUPPLEMENTS}

Table S-1. Relative quantification of the metabolites isolated from the B. napus seedlings germinated for 24 hours in the presence and absence of clinorotation

\begin{tabular}{|c|c|c|c|c|c|c|c|c|c|}
\hline \multirow{2}{*}{ Metabolites } & \multirow{2}{*}{$t_{R}$} & \multicolumn{3}{|c|}{ Control } & \multicolumn{3}{|c|}{ Clinorotation } & \multirow{2}{*}{$\begin{array}{c}\text { Fold change } \\
\text { (Clinorotation/ } \\
\text { Control) }\end{array}$} & \multirow{2}{*}{ t-test } \\
\hline & & 1 & 2 & 3 & 1 & 2 & 3 & & \\
\hline Mannose (1) (1 MEOX) (5TMS) & 28.2 & $7.16 \mathrm{E}+06$ & $1.60 \mathrm{E}+07$ & $5.38 \mathrm{E}+06$ & $2.18 \mathrm{E}+07$ & $2.19 \mathrm{E}+07$ & $1.40 E+06$ & 1.58 & 0.51 \\
\hline Lysine (4TMS) & 29.0 & $2.79 \mathrm{E}+09$ & $2.79 E+09$ & NA & $3.34 \mathrm{E}+09$ & $5.17 \mathrm{E}+09$ & $3.90 E+09$ & 1.48 & - \\
\hline Unknown RT 33.45 & 33.5 & $2.54 \mathrm{E}+09$ & $3.09 E+09$ & $6.76 E+09$ & $1.17 \mathrm{E}+10$ & $3.31 \mathrm{E}+09$ & $2.32 E+09$ & 1.40 & 0.64 \\
\hline Pyroglutamic acid (2TMS) & 20.1 & $1.07 E+08$ & $8.65 \mathrm{E}+07$ & $6.03 E+07$ & $1.18 \mathrm{E}+08$ & $1.20 \mathrm{E}+08$ & $1.16 \mathrm{E}+08$ & 1.39 & 0.07 \\
\hline Methionine (2TMS) & 20.0 & $3.36 \mathrm{E}+07$ & $1.71 \mathrm{E}+07$ & $1.89 \mathrm{E}+07$ & $2.86 \mathrm{E}+07$ & $4.27 E+07$ & $2.08 \mathrm{E}+07$ & 1.32 & 0.42 \\
\hline Glycerinic acid(3TMS) & 15.2 & $7.60 \mathrm{E}+09$ & $3.21 \mathrm{E}+09$ & $2.75 \mathrm{E}+09$ & $4.58 \mathrm{E}+09$ & $6.11 \mathrm{E}+09$ & $6.73 E+09$ & 1.29 & 0.48 \\
\hline Phenylalanine (2TMS) & 22.6 & $1.42 \mathrm{E}+08$ & $1.16 \mathrm{E}+08$ & $1.02 E+08$ & $1.35 E+08$ & $1.90 E+08$ & $1.19 E+08$ & 1.23 & 0.32 \\
\hline Isoleucine (2TMS) & 14.2 & $4.41 \mathrm{E}+09$ & $3.73 E+09$ & $3.63 \mathrm{E}+09$ & $4.93 E+09$ & $4.25 E+09$ & $4.15 \mathrm{E}+09$ & 1.13 & 0.20 \\
\hline Cysteine(tentative) (3TMS) & 20.9 & $2.86 \mathrm{E}+09$ & NA & $9.41 \mathrm{E}+08$ & $1.63 E+09$ & $2.16 \mathrm{E}+09$ & $2.54 \mathrm{E}+09$ & 1.11 & - \\
\hline Phosphate (3TMS) & 13.6 & $3.21 \mathrm{E}+10$ & $2.83 E+10$ & $2.30 \mathrm{E}+10$ & $3.06 \mathrm{E}+10$ & $3.60 E+10$ & $2.49 \mathrm{E}+10$ & 1.10 & 0.55 \\
\hline Synapic acid (trans-)(2TMS) & 35.07 & $2.33 \mathrm{E}+08$ & $2.70 E+08$ & $4.50 E+08$ & $5.02 E+08$ & $3.57 E+08$ & $1.81 \mathrm{E}+08$ & 1.09 & 0.81 \\
\hline Pentafuranose (4TMS) & 25.8 & $3.02 \mathrm{E}+09$ & $3.02 \mathrm{E}+09$ & NA & $3.21 \mathrm{E}+09$ & $3.41 \mathrm{E}+09$ & $3.21 \mathrm{E}+09$ & 1.08 & - \\
\hline Valine (2TMS) & 12.1 & $1.01 \mathrm{E}+10$ & $7.63 E+09$ & $6.89 E+09$ & $8.72 E+09$ & $1.07 \mathrm{E}+10$ & $7.10 \mathrm{E}+09$ & 1.08 & 0.68 \\
\hline Proline (2TMS) & 14.3 & $4.21 \mathrm{E}+10$ & $2.68 \mathrm{E}+10$ & $2.77 \mathrm{E}+10$ & $3.74 \mathrm{E}+10$ & $3.46 \mathrm{E}+10$ & $3.17 \mathrm{E}+10$ & 1.07 & 0.68 \\
\hline Glycine (3TMS) & 14.5 & $5.47 \mathrm{E}+09$ & $4.75 E+09$ & $1.93 \mathrm{E}+09$ & $2.82 \mathrm{E}+09$ & $5.04 E+09$ & $5.11 \mathrm{E}+09$ & 1.07 & 0.85 \\
\hline Asparagine (4TMS) & 22.6 & $4.00 \mathrm{E}+07$ & $1.09 \mathrm{E}+07$ & $2.53 \mathrm{E}+07$ & $2.01 \mathrm{E}+07$ & $4.59 \mathrm{E}+07$ & $1.50 E+07$ & 1.06 & 0.91 \\
\hline Threonine (3TMS) & 16.7 & $1.86 \mathrm{E}+10$ & $1.47 \mathrm{E}+10$ & $1.30 \mathrm{E}+10$ & $1.61 \mathrm{E}+10$ & $1.64 \mathrm{E}+10$ & NA & 1.06 & - \\
\hline Saccharide (tentative) & 30.1 & $6.17 \mathrm{E}+09$ & $4.06 \mathrm{E}+09$ & $4.40 \mathrm{E}+09$ & $5.49 \mathrm{E}+09$ & $5.77 E+09$ & $4.20 E+09$ & 1.06 & 0.75 \\
\hline Phosphosaccharide (tentative) & 25.6 & $3.36 \mathrm{E}+09$ & $2.51 E+09$ & $2.45 \mathrm{E}+09$ & $2.64 \mathrm{E}+09$ & $4.31 \mathrm{E}+09$ & $1.83 E+09$ & 1.05 & 0.86 \\
\hline Tyrosine (3TMS) & 29.3 & $8.12 E+09$ & $7.51 \mathrm{E}+09$ & $6.99 E+09$ & $7.49 E+09$ & $9.97 \mathrm{E}+09$ & $5.86 \mathrm{E}+09$ & 1.03 & 0.86 \\
\hline Alanine (2TMS) & 9.0 & $4.09 \mathrm{E}+10$ & $4.72 \mathrm{E}+10$ & $3.10 E+10$ & $3.43 E+10$ & $6.03 E+10$ & $2.62 \mathrm{E}+10$ & 1.01 & 0.96 \\
\hline Glutamine (3TMS) & 25.9 & $1.82 \mathrm{E}+10$ & $1.36 \mathrm{E}+10$ & $1.15 E+10$ & $1.77 \mathrm{E}+10$ & $1.11 \mathrm{E}+10$ & $1.43 E+10$ & 1.00 & 0.99 \\
\hline 2-Monostearate-glycerol(2TMS) & 43.1 & $4.25 \mathrm{E}+07$ & $3.37 \mathrm{E}+07$ & $3.59 \mathrm{E}+07$ & $3.90 \mathrm{E}+07$ & $2.97 \mathrm{E}+07$ & $4.25 \mathrm{E}+07$ & 0.99 & 0.96 \\
\hline Oxypropyl ester of stearic acid(2TMS) & 43.7 & $8.03 E+09$ & $8.32 E+09$ & $7.72 \mathrm{E}+09$ & $6.04 \mathrm{E}+09$ & $9.03 E+09$ & $8.82 \mathrm{E}+09$ & 0.99 & 0.95 \\
\hline Serine(3TMS) & 16.0 & $5.26 \mathrm{E}+10$ & $4.50 \mathrm{E}+10$ & $3.50 E+10$ & $4.82 \mathrm{E}+10$ & $5.01 \mathrm{E}+10$ & $3.23 E+10$ & 0.99 & 0.94 \\
\hline y-aminoisobutyric acid (3TMS) & 20.3 & $9.01 \mathrm{E}+07$ & $1.03 E+08$ & $8.44 \mathrm{E}+07$ & $7.94 \mathrm{E}+07$ & $1.43 \mathrm{E}+08$ & $4.94 \mathrm{E}+07$ & 0.98 & 0.95 \\
\hline RT 25.01 & 25.0 & $1.40 \mathrm{E}+10$ & $4.13 E+09$ & $7.89 \mathrm{E}+09$ & $6.96 \mathrm{E}+09$ & $9.52 \mathrm{E}+09$ & $8.63 E+09$ & 0.96 & 0.92 \\
\hline Fumarate (2TMS) & 15.8 & $6.41 \mathrm{E}+09$ & $5.88 \mathrm{E}+09$ & $4.30 E+09$ & $4.42 E+09$ & $6.44 \mathrm{E}+09$ & $5.08 \mathrm{E}+09$ & 0.96 & 0.82 \\
\hline Ethanolamine(3TMS) & 13.4 & $6.33 \mathrm{E}+09$ & $5.70 E+09$ & NA & $5.77 E+09$ & $7.57 E+09$ & $4.00 E+09$ & 0.96 & - \\
\hline Galactose (1) (1MEOX) (5TMS) & 28.3 & $7.75 \mathrm{E}+07$ & $7.26 \mathrm{E}+07$ & $5.41 \mathrm{E}+07$ & $5.61 \mathrm{E}+07$ & $7.90 \mathrm{E}+07$ & $6.04 \mathrm{E}+07$ & 0.96 & 0.79 \\
\hline Saccharide (tentative) & 32.1 & $4.24 \mathrm{E}+09$ & NA & $4.01 E+09$ & $3.86 \mathrm{E}+09$ & $3.90 \mathrm{E}+09$ & $4.01 \mathrm{E}+09$ & 0.95 & - \\
\hline Palmitic acid(1TMS) & 31.5 & 2.10E+10 & $1.58 \mathrm{E}+10$ & $1.09 \mathrm{E}+10$ & $1.18 \mathrm{E}+10$ & $1.81 \mathrm{E}+10$ & $1.41 \mathrm{E}+10$ & 0.92 & 0.74 \\
\hline Succinic acid (2TMS) & 14.8 & $4.34 \mathrm{E}+09$ & $3.51 \mathrm{E}+09$ & $1.68 \mathrm{E}+09$ & $2.54 \mathrm{E}+09$ & NA & $3.21 \mathrm{E}+09$ & 0.90 & - \\
\hline
\end{tabular}




\begin{tabular}{|c|c|c|c|c|c|c|c|c|c|}
\hline \multirow{2}{*}{ Metabolites } & \multirow{2}{*}{$t_{R}$} & \multicolumn{3}{|c|}{ Control } & \multicolumn{3}{|c|}{ Clinorotation } & \multirow{2}{*}{$\begin{array}{l}\text { Fold change } \\
\text { (Clinorotation/ } \\
\text { Control) }\end{array}$} & \multirow{2}{*}{ t-test } \\
\hline & & 1 & 2 & 3 & 1 & 2 & 3 & & \\
\hline 1-Monopalmytat-glycerol (2TMS) & 40.8 & $8.32 E+08$ & $8.80 \mathrm{E}+08$ & $6.63 \mathrm{E}+08$ & $6.35 E+08$ & $7.51 \mathrm{E}+08$ & $7.40 \mathrm{E}+08$ & 0.90 & 0.33 \\
\hline Myoinositol(6TMS) & 32.2 & $5.88 \mathrm{E}+10$ & $4.74 \mathrm{E}+10$ & $4.71 \mathrm{E}+10$ & $4.26 \mathrm{E}+10$ & $4.86 \mathrm{E}+10$ & $4.55 E+10$ & 0.89 & 0.26 \\
\hline D-Fructose-6-Phosphate(1 MEOX) (6TMS) & 36.1 & $4.61 \mathrm{E}+09$ & $4.29 \mathrm{E}+09$ & $3.84 \mathrm{E}+09$ & $3.60 \mathrm{E}+09$ & $4.39 \mathrm{E}+09$ & $3.34 \mathrm{E}+09$ & 0.89 & 0.30 \\
\hline Xylose (2) (4TMS) & 23.3 & $4.24 \mathrm{E}+09$ & NA & $2.25 E+09$ & $2.54 \mathrm{E}+09$ & $2.59 E+09$ & $3.50 E+09$ & 0.89 & - \\
\hline Stearic acid(1TMS) & 35.1 & $4.11 \mathrm{E}+08$ & $4.77 \mathrm{E}+08$ & $2.17 \mathrm{E}+08$ & $2.72 \mathrm{E}+08$ & $4.04 \mathrm{E}+08$ & $2.98 \mathrm{E}+08$ & 0.88 & 0.65 \\
\hline Aspartic acid (3TMS) & 20.1 & $6.22 \mathrm{E}+10$ & $5.49 E+10$ & $4.15 E+10$ & $4.78 \mathrm{E}+10$ & $5.29 \mathrm{E}+10$ & $3.91 \mathrm{E}+10$ & 0.88 & 0.44 \\
\hline Histidine (3TMS) & 28.9 & $7.47 \mathrm{E}+07$ & $3.08 \mathrm{E}+07$ & $4.08 \mathrm{E}+07$ & $3.36 \mathrm{E}+07$ & $5.85 \mathrm{E}+07$ & $3.50 E+07$ & 0.87 & 0.70 \\
\hline Tryptophane (3TMS) & 34.5 & $4.84 \mathrm{E}+09$ & $4.25 E+09$ & $5.07 E+09$ & $3.99 \mathrm{E}+09$ & $4.67 E+09$ & $3.64 E+09$ & 0.87 & 0.18 \\
\hline Glutamine (3TMS) & 22.5 & $1.43 \mathrm{E}+11$ & $1.22 \mathrm{E}+11$ & $1.06 \mathrm{E}+11$ & $9.70 \mathrm{E}+10$ & $1.33 \mathrm{E}+11$ & $9.03 \mathrm{E}+10$ & 0.86 & 0.37 \\
\hline Galactose (2) (1 MEOX) (5TMS) & 28.7 & $1.32 E+09$ & NA & $1.04 \mathrm{E}+09$ & NA & $9.96 \mathrm{E}+08$ & NA & 0.84 & - \\
\hline Asparagine (3TMS) & 23.6 & $1.68 \mathrm{E}+10$ & $1.49 \mathrm{E}+10$ & $1.42 \mathrm{E}+10$ & $1.73 \mathrm{E}+10$ & $1.32 \mathrm{E}+10$ & $8.28 \mathrm{E}+09$ & 0.84 & 0.43 \\
\hline Malic acid (3TMS) & 19.3 & $3.62 E+11$ & $3.14 \mathrm{E}+11$ & $2.64 \mathrm{E}+11$ & $2.45 E+11$ & $3.66 \mathrm{E}+11$ & $1.80 E+11$ & 0.84 & 0.46 \\
\hline Fructose (1) (1 MEOX) (5TMS) & 27.9 & $1.76 \mathrm{E}+11$ & $8.63 E+10$ & $7.38 \mathrm{E}+10$ & $8.38 \mathrm{E}+10$ & $7.10 \mathrm{E}+10$ & $1.27 \mathrm{E}+11$ & 0.84 & 0.65 \\
\hline Ribonic acid(tentative) (5TMS) & 25.4 & $3.49 E+09$ & $4.76 \mathrm{E}+09$ & $2.81 \mathrm{E}+09$ & $3.30 E+09$ & $4.19 E+09$ & $1.64 \mathrm{E}+09$ & 0.82 & 0.53 \\
\hline Disaccharide derived acid & 30.4 & $7.22 \mathrm{E}+09$ & $6.20 \mathrm{E}+09$ & $8.05 E+09$ & $5.18 \mathrm{E}+09$ & $8.71 \mathrm{E}+09$ & $3.62 E+09$ & 0.82 & 0.45 \\
\hline Oligosaccharide & 52.4 & $6.56 \mathrm{E}+07$ & $5.79 \mathrm{E}+07$ & $8.30 \mathrm{E}+07$ & $6.30 \mathrm{E}+07$ & $6.16 \mathrm{E}+07$ & $4.36 \mathrm{E}+07$ & 0.81 & 0.26 \\
\hline Fructose (2) (1MEOX) (5TMS) & 28.1 & 1.17E+11 & $5.84 \mathrm{E}+10$ & $5.11 \mathrm{E}+10$ & $5.18 \mathrm{E}+10$ & $4.63 \mathrm{E}+10$ & $8.60 E+10$ & 0.81 & 0.59 \\
\hline Glucose (2) (1MEOX) (5TMS) & 28.8 & $4.59 \mathrm{E}+10$ & $3.30 \mathrm{E}+10$ & $2.28 \mathrm{E}+10$ & $2.63 \mathrm{E}+10$ & $2.57 E+10$ & $3.00 E+10$ & 0.81 & 0.39 \\
\hline Unknown RT 33.01 & 33.0 & $4.78 \mathrm{E}+09$ & $2.88 \mathrm{E}+09$ & $5.04 \mathrm{E}+09$ & $2.84 \mathrm{E}+09$ & $4.28 \mathrm{E}+09$ & $3.03 E+09$ & 0.80 & 0.36 \\
\hline Glycerine (3TMS) & 13.7 & $7.46 \mathrm{E}+07$ & $5.89 \mathrm{E}+07$ & $3.95 \mathrm{E}+07$ & $5.20 \mathrm{E}+07$ & 4.17E+07 & $4.45 \mathrm{E}+07$ & 0.80 & 0.33 \\
\hline Glucose (1) (1MEOX) (5TMS) & 28.4 & $3.68 \mathrm{E}+11$ & $2.73 E+11$ & $1.92 E+11$ & $2.01 \mathrm{E}+11$ & $2.07 E+11$ & $2.39 E+11$ & 0.78 & 0.30 \\
\hline Synapic acid (2TMS) & 31.6 & $2.74 \mathrm{E}+07$ & $2.14 \mathrm{E}+07$ & $2.52 E+07$ & $2.45 \mathrm{E}+07$ & $1.74 \mathrm{E}+07$ & $1.41 \mathrm{E}+07$ & 0.76 & 0.17 \\
\hline Sorbitol (6TMS) & 29.2 & $6.07 E+09$ & $4.73 E+09$ & $6.22 E+09$ & $3.97 E+09$ & $5.75 E+09$ & $2.89 E+09$ & 0.74 & 0.20 \\
\hline Dehydroascorbic acid dimer (2MEOX) & 27.4 & $2.61 \mathrm{E}+09$ & NA & NA & $1.54 \mathrm{E}+09$ & NA & $2.29 \mathrm{E}+09$ & 0.73 & - \\
\hline Unknown RT 48.68 & 48.7 & $2.52 \mathrm{E}+09$ & $3.34 \mathrm{E}+09$ & $1.54 \mathrm{E}+09$ & $1.32 \mathrm{E}+09$ & $3.30 E+09$ & $7.78 \mathrm{E}+08$ & 0.73 & 0.51 \\
\hline Glucose-6-Phosphate (1MEOX) (6TMS) & 36.3 & $8.50 E+09$ & $8.83 E+09$ & $8.24 \mathrm{E}+09$ & $5.40 E+09$ & $7.29 E+09$ & $5.79 E+09$ & 0.72 & 0.02 \\
\hline Citric acid (4TMS) & 26.9 & $1.83 E+11$ & $1.68 \mathrm{E}+11$ & $1.55 E+11$ & $8.10 E+10$ & $1.97 \mathrm{E}+11$ & $8.83 E+10$ & 0.72 & 0.29 \\
\hline Sucrose & 41.4 & $9.45 \mathrm{E}+10$ & $1.12 \mathrm{E}+11$ & $1.09 E+11$ & $7.73 E+10$ & $1.04 \mathrm{E}+11$ & $4.58 \mathrm{E}+10$ & 0.72 & 0.17 \\
\hline Disaccharide & 41.9 & $5.46 \mathrm{E}+12$ & $6.26 \mathrm{E}+12$ & $6.06 \mathrm{E}+12$ & $4.38 \mathrm{E}+12$ & $5.80 \mathrm{E}+12$ & $2.60 \mathrm{E}+12$ & 0.72 & 0.16 \\
\hline Galactinol (9TMS) & 46.6 & $2.38 \mathrm{E}+10$ & $3.80 E+10$ & $2.90 E+10$ & $2.25 E+10$ & $3.00 E+10$ & $1.20 E+10$ & 0.71 & 0.26 \\
\hline Raffinose & 51.8 & $3.14 \mathrm{E}+10$ & $5.33 \mathrm{E}+10$ & $4.81 \mathrm{E}+10$ & $3.25 E+10$ & $4.53 \mathrm{E}+10$ & $1.28 \mathrm{E}+10$ & 0.68 & 0.29 \\
\hline Unknown RT 27.6 & 27.6 & $2.26 \mathrm{E}+09$ & $1.38 \mathrm{E}+09$ & NA & $1.02 E+09$ & NA & $9.79 E+08$ & 0.55 & - \\
\hline
\end{tabular}

Analyte abundances were calculated as integrated peak areas; $t_{R}$, retention time; (tentative) indicates tentative identification; the order of metabolites in the table corresponds to the descending values of fold changes; NA-not detected. 
Table S-2. Relative quantification of the metabolites isolated from the $B$. napus seedlings germinated for 48 hours in the presence and absence of clinorotation

\begin{tabular}{|c|c|c|c|c|c|c|c|c|c|}
\hline \multirow{2}{*}{ Metabolites } & \multirow{2}{*}{$t_{R}$} & \multicolumn{3}{|c|}{ Control } & \multicolumn{3}{|c|}{ Clinorotation } & \multirow{2}{*}{$\begin{array}{c}\text { Fold change } \\
\text { (Clinorotation/ } \\
\text { Control) }\end{array}$} & \multirow{2}{*}{ t-test } \\
\hline & & 1 & 2 & 3 & 1 & 2 & 3 & & \\
\hline Glyceric acid(3 TMS) & 15.2 & $4.53 E+10$ & $2.97 E+10$ & $6.58 \mathrm{E}+10$ & $9.37 E+10$ & $4.83 E+10$ & $1.58 \mathrm{E}+11$ & 2.13 & 0.19 \\
\hline Aspartic acid (3 TMS) & 20.12 & $8.46 \mathrm{E}+09$ & $4.27 \mathrm{E}+09$ & $1.47 \mathrm{E}+10$ & $1.44 \mathrm{E}+10$ & $1.43 \mathrm{E}+10$ & $2.74 \mathrm{E}+10$ & 2.05 & 0.15 \\
\hline Synapic acid (2 TMS) & 31.6 & $8.07 E+06$ & NA & $1.72 E+07$ & $1.81 \mathrm{E}+07$ & NA & $2.77 E+07$ & 1.81 & 0.26 \\
\hline Galactose (2) (1 MEOX) (5TMS) & 28.7 & $7.52 E+08$ & NA & $9.41 \mathrm{E}+08$ & $1.71 \mathrm{E}+09$ & $5.19 \mathrm{E}+08$ & $1.76 \mathrm{E}+09$ & 1.57 & 0.43 \\
\hline Ethanolamine (3 TMS) & 13.4 & $7.33 E+09$ & $2.56 \mathrm{E}+09$ & $9.45 \mathrm{E}+09$ & $1.12 \mathrm{E}+10$ & NA & $8.93 E+09$ & 1.57 & - \\
\hline RT 34.24 & 34.2 & $9.23 E+08$ & NA & $1.61 \mathrm{E}+09$ & $1.97 E+09$ & NA & NA & 1.56 & - \\
\hline Glucose (1) (1MEOX) (5TMS) & 28.4 & $6.24 \mathrm{E}+11$ & $4.27 E+11$ & $1.13 E+12$ & $1.18 \mathrm{E}+12$ & $4.95 E+11$ & $1.56 \mathrm{E}+12$ & 1.49 & 0.40 \\
\hline Glucose (2) (1MEOX) (5TMS) & 28.8 & $7.07 E+10$ & $5.05 \mathrm{E}+10$ & $1.23 \mathrm{E}+11$ & $1.29 \mathrm{E}+11$ & $5.67 \mathrm{E}+10$ & $1.66 \mathrm{E}+11$ & 1.44 & 0.41 \\
\hline Fructose (1) (1MEOX) (5TMS) & 27.9 & $2.57 E+11$ & $1.84 \mathrm{E}+11$ & $5.07 E+11$ & $4.69 E+11$ & $1.77 \mathrm{E}+11$ & $5.83 E+11$ & 1.30 & 0.58 \\
\hline Glycine (3 TMS) & 14.5 & $3.61 \mathrm{E}+09$ & $1.77 \mathrm{E}+09$ & $7.89 \mathrm{E}+09$ & $5.56 \mathrm{E}+09$ & $3.55 \mathrm{E}+09$ & $7.73 E+09$ & 1.27 & 0.61 \\
\hline 2-Monostearate-glycerol(2TMS) & 43.1 & $3.63 E+07$ & $1.79 \mathrm{E}+07$ & $3.10 \mathrm{E}+07$ & $4.34 \mathrm{E}+07$ & $2.28 \mathrm{E}+07$ & $4.19 \mathrm{E}+07$ & 1.27 & 0.42 \\
\hline Fructose (2) (1 MEOX) (5 TMS) & 28.1 & $1.74 \mathrm{E}+11$ & $1.32 \mathrm{E}+11$ & $3.40 \mathrm{E}+11$ & $3.07 E+11$ & $1.22 \mathrm{E}+11$ & $3.84 \mathrm{E}+11$ & 1.26 & 0.61 \\
\hline Stearic acid(1TMS) & 35.13 & $2.12 \mathrm{E}+08$ & $1.57 \mathrm{E}+08$ & $2.79 E+08$ & $3.16 \mathrm{E}+08$ & $1.57 \mathrm{E}+08$ & $3.23 E+08$ & 1.23 & 0.49 \\
\hline Palmitic acid(1TMS) & 31.5 & $1.04 \mathrm{E}+10$ & $6.31 \mathrm{E}+09$ & $1.39 \mathrm{E}+10$ & $1.19 \mathrm{E}+10$ & $8.58 \mathrm{E}+09$ & $1.66 \mathrm{E}+10$ & 1.21 & 0.54 \\
\hline Galactose (1) (1 MEOX) (5 TMS) & 28.3 & $7.65 \mathrm{E}+07$ & $3.12 \mathrm{E}+07$ & $1.13 E+08$ & $1.28 \mathrm{E}+08$ & $4.73 \mathrm{E}+07$ & $9.08 \mathrm{E}+07$ & 1.21 & 0.67 \\
\hline Proline ( 2TMS) & 14.3 & $3.42 \mathrm{E}+10$ & $1.63 \mathrm{E}+10$ & NA & $4.67 E+10$ & $1.36 \mathrm{E}+10$ & $3.09 E+10$ & 1.20 & - \\
\hline Pyroglutamic acid (2 TMS) & 20.07 & $1.01 E+08$ & $6.15 E+07$ & $2.07 E+08$ & $1.61 \mathrm{E}+08$ & $7.45 E+07$ & $2.04 \mathrm{E}+08$ & 1.19 & 0.71 \\
\hline y-aminoisobutyric acid (3 TMS) & 20.32 & $3.56 \mathrm{E}+07$ & $1.85 \mathrm{E}+07$ & $6.91 \mathrm{E}+07$ & $5.91 \mathrm{E}+07$ & $2.51 \mathrm{E}+07$ & $6.19 \mathrm{E}+07$ & 1.19 & 0.71 \\
\hline Histidine (3 TMS) & 28.9 & $6.03 E+07$ & $3.77 E+07$ & $1.27 E+08$ & $1.19 \mathrm{E}+08$ & $3.58 \mathrm{E}+07$ & $1.11 \mathrm{E}+08$ & 1.18 & 0.74 \\
\hline Fumarate (2 TMS) & 15.8 & 1.57E+09 & $2.28 \mathrm{E}+09$ & $6.88 \mathrm{E}+09$ & $4.11 \mathrm{E}+09$ & $2.78 \mathrm{E}+09$ & $5.72 \mathrm{E}+09$ & 1.18 & 0.75 \\
\hline Glycerine (3TMS) & 13.7 & $6.61 \mathrm{E}+07$ & $1.50 \mathrm{E}+07$ & $8.13 E+07$ & $8.12 \mathrm{E}+07$ & $4.79 \mathrm{E}+07$ & $6.07 E+07$ & 1.17 & 0.70 \\
\hline Saccharide (tentative) & 29.7 & $3.77 E+09$ & $2.24 \mathrm{E}+09$ & $4.52 E+09$ & $4.69 E+09$ & $2.36 \mathrm{E}+09$ & $5.14 \mathrm{E}+09$ & 1.16 & 0.64 \\
\hline Synapic acid (trans-) (2 TMS) & 35.07 & $7.17 E+06$ & $8.55 \mathrm{E}+06$ & $1.46 \mathrm{E}+08$ & $9.10 \mathrm{E}+07$ & $5.05 \mathrm{E}+07$ & $4.06 \mathrm{E}+07$ & 1.13 & 0.89 \\
\hline Oxypropyl ester of stearic acid(2 TMS) & 43.7 & $6.08 \mathrm{E}+09$ & 4.13E+09 & 7.67E+09 & $6.93 \mathrm{E}+09$ & $4.23 E+09$ & 8.87E+09 & 1.12 & 0.69 \\
\hline Phosphate (3 TMS) & 13.6 & $5.24 \mathrm{E}+10$ & $2.58 \mathrm{E}+10$ & $1.04 \mathrm{E}+11$ & $8.78 \mathrm{E}+10$ & $3.26 \mathrm{E}+10$ & $8.24 \mathrm{E}+10$ & 1.11 & 0.82 \\
\hline Galactinol (9 TMS) & 46.6 & $3.00 \mathrm{E}+09$ & $1.98 \mathrm{E}+09$ & $5.18 \mathrm{E}+09$ & 4.17E+09 & $3.40 \mathrm{E}+09$ & $3.51 \mathrm{E}+09$ & 1.09 & 0.77 \\
\hline Xylose (4 TMS) & 23.3 & $5.27 E+09$ & $3.30 E+09$ & $8.03 E+09$ & $7.06 \mathrm{E}+09$ & $3.36 \mathrm{E}+09$ & $7.50 E+09$ & 1.08 & 0.83 \\
\hline Unknown RT 27.6 & 27.6 & $4.79 \mathrm{E}+08$ & NA & $1.42 E+09$ & $1.01 \mathrm{E}+09$ & NA & NA & 1.06 & - \\
\hline Succinic acid (2 TMS) & 14.8 & $2.24 \mathrm{E}+09$ & $1.50 \mathrm{E}+09$ & $5.85 \mathrm{E}+09$ & $3.99 \mathrm{E}+09$ & NA & 2.77E+09 & 1.06 & - \\
\hline Saccharide (tentative) & 31.1 & $1.97 E+09$ & $1.15 E+09$ & $3.02 E+09$ & $2.35 \mathrm{E}+09$ & $1.38 \mathrm{E}+09$ & $2.65 \mathrm{E}+09$ & 1.04 & 0.91 \\
\hline Phosphosaccharide & 25.6 & $2.91 \mathrm{E}+09$ & $2.51 E+09$ & $3.73 E+09$ & $4.62 \mathrm{E}+09$ & $2.24 \mathrm{E}+09$ & $2.54 \mathrm{E}+09$ & 1.03 & 0.93 \\
\hline 1-Monopalmytat-glycerol (2 TMS) & 40.8 & $6.47 E+08$ & $4.67 \mathrm{E}+08$ & $8.04 \mathrm{E}+08$ & $7.15 E+08$ & 4.17E+08 & $8.29 E+08$ & 1.02 & 0.93 \\
\hline Pentafuranose (4 TMS) & 25.8 & $4.43 E+09$ & $3.08 \mathrm{E}+09$ & $4.33 E+09$ & $5.39 E+09$ & $2.96 \mathrm{E}+09$ & $3.61 E+09$ & 1.01 & 0.96 \\
\hline Xylose (4 TMS) & 23.1 & $1.32 \mathrm{E}+09$ & NA & $2.18 \mathrm{E}+09$ & $2.03 E+09$ & NA & $1.50 \mathrm{E}+09$ & 1.01 & - \\
\hline Glutamine (3 TMS) & 25.9 & $4.98 \mathrm{E}+10$ & $2.16 \mathrm{E}+10$ & $5.21 \mathrm{E}+10$ & $4.59 \mathrm{E}+10$ & $2.92 \mathrm{E}+10$ & 4.86E+10 & 1.00 & 1.00 \\
\hline Sorbitol (6 TMS) & 29.2 & $3.20 \mathrm{E}+09$ & $1.25 \mathrm{E}+09$ & $3.73 E+09$ & $3.08 \mathrm{E}+09$ & NA & $2.32 \mathrm{E}+09$ & 0.99 & - \\
\hline Methionine (2 TMS) & 20.03 & $2.59 \mathrm{E}+07$ & $1.70 E+07$ & $4.39 \mathrm{E}+07$ & $4.35 E+07$ & $1.90 \mathrm{E}+07$ & $2.27 \mathrm{E}+07$ & 0.98 & 0.97 \\
\hline
\end{tabular}




\begin{tabular}{|c|c|c|c|c|c|c|c|c|c|}
\hline \multirow{2}{*}{ Metabolites } & \multirow{2}{*}{$t_{R}$} & \multicolumn{3}{|c|}{ Control } & \multicolumn{3}{|c|}{ Clinorotation } & \multirow{2}{*}{$\begin{array}{c}\text { Fold change } \\
\text { (Clinorotation/ } \\
\text { Control) }\end{array}$} & \multirow{2}{*}{ t-test } \\
\hline & & 1 & 2 & 3 & 1 & 2 & 3 & & \\
\hline 4-Hydroxyproline(trans-) (3 TMS) & 20.2 & $4.70 E+09$ & $3.29 \mathrm{E}+09$ & $1.25 \mathrm{E}+10$ & $9.98 \mathrm{E}+09$ & $3.06 E+09$ & NA & 0.95 & - \\
\hline Valine (2 TMS) & 12.1 & $1.60 E+10$ & $7.92 \mathrm{E}+09$ & $3.36 \mathrm{E}+10$ & $2.33 \mathrm{E}+10$ & $9.39 E+09$ & $2.21 \mathrm{E}+10$ & 0.95 & 0.92 \\
\hline Tryptophane (3 TMS) & 34.5 & $6.00 E+09$ & $2.61 E+09$ & NA & $4.91 \mathrm{E}+09$ & $2.94 \mathrm{E}+09$ & $4.41 E+09$ & 0.95 & - \\
\hline Threonine (3 TMS) & 16.7 & $1.90 \mathrm{E}+10$ & $8.76 \mathrm{E}+09$ & $3.44 \mathrm{E}+10$ & $2.81 \mathrm{E}+10$ & $9.11 \mathrm{E}+09$ & $2.12 \mathrm{E}+10$ & 0.94 & 0.90 \\
\hline Myoinositol(6 TMS) & 32.2 & $5.02 E+10$ & $2.79 \mathrm{E}+10$ & $7.16 \mathrm{E}+10$ & $6.79 E+10$ & $2.46 \mathrm{E}+10$ & $4.81 \mathrm{E}+10$ & 0.94 & 0.87 \\
\hline Lysine (4 TMS) & 29.0 & $6.54 \mathrm{E}+09$ & $5.24 \mathrm{E}+09$ & $1.85 \mathrm{E}+10$ & $8.34 \mathrm{E}+09$ & $5.91 E+09$ & $1.39 \mathrm{E}+10$ & 0.93 & 0.89 \\
\hline Saccharide (?) & 30.1 & $1.11 \mathrm{E}+10$ & $6.36 \mathrm{E}+09$ & $1.27 \mathrm{E}+10$ & $1.18 \mathrm{E}+10$ & $6.51 \mathrm{E}+09$ & $8.98 \mathrm{E}+09$ & 0.91 & 0.72 \\
\hline Asparagine (3 TMS) & 23.6 & $1.08 \mathrm{E}+10$ & $5.48 \mathrm{E}+09$ & $1.66 \mathrm{E}+10$ & $1.28 \mathrm{E}+10$ & $5.71 E+09$ & $1.07 \mathrm{E}+10$ & 0.89 & 0.76 \\
\hline Unknown RT 48.68 & 48.7 & $2.83 E+09$ & $2.25 \mathrm{E}+09$ & $5.20 E+09$ & $3.27 E+09$ & $1.32 \mathrm{E}+09$ & $4.48 \mathrm{E}+09$ & 0.88 & 0.77 \\
\hline Disaccharide derived acid (tentative) & 31.3 & $1.34 \mathrm{E}+09$ & NA & $1.58 \mathrm{E}+09$ & $1.37 \mathrm{E}+09$ & NA & $1.16 \mathrm{E}+09$ & 0.87 & - \\
\hline Glucose-6-Phosphate (1 MEOX) (6 TMS) & 36.28 & $7.35 \mathrm{E}+09$ & $3.40 E+09$ & $8.27 E+09$ & $7.77 \mathrm{E}+09$ & $2.97 E+09$ & $5.70 E+09$ & 0.86 & 0.69 \\
\hline Alanine (2 TMS) & 9.0 & $1.47 \mathrm{E}+10$ & $7.70 E+09$ & $6.03 E+10$ & $2.79 \mathrm{E}+10$ & $1.00 \mathrm{E}+10$ & $2.76 \mathrm{E}+10$ & 0.79 & 0.76 \\
\hline D-Fructose-6-Phosphate(1 MEOX) (6 TMS) & 36.1 & $4.30 E+09$ & $1.80 \mathrm{E}+09$ & $4.61 \mathrm{E}+09$ & $3.58 \mathrm{E}+09$ & $2.45 \mathrm{E}+09$ & $2.24 \mathrm{E}+09$ & 0.77 & 0.46 \\
\hline Serine (3 TMS) & 16.0 & $2.53 \mathrm{E}+10$ & $1.26 \mathrm{E}+10$ & $4.71 \mathrm{E}+10$ & $3.02 \mathrm{E}+10$ & $1.07 \mathrm{E}+10$ & $2.46 \mathrm{E}+10$ & 0.77 & 0.61 \\
\hline Glutamine (3 TMS) & 22.5 & $5.35 \mathrm{E}+10$ & $1.91 \mathrm{E}+10$ & $8.08 \mathrm{E}+10$ & $6.08 \mathrm{E}+10$ & $1.82 \mathrm{E}+10$ & $3.86 \mathrm{E}+10$ & 0.77 & 0.61 \\
\hline Tyrosine (3 TMS) & 29.3 & $1.18 \mathrm{E}+10$ & $4.78 \mathrm{E}+09$ & $1.71 \mathrm{E}+10$ & $1.11 \mathrm{E}+10$ & $4.99 E+09$ & $9.04 \mathrm{E}+09$ & 0.75 & 0.52 \\
\hline Unknown RT 33.01 & 33.0 & $2.45 \mathrm{E}+09$ & $8.91 \mathrm{E}+08$ & $3.06 \mathrm{E}+09$ & $1.48 \mathrm{E}+09$ & $1.70 \mathrm{E}+09$ & NA & 0.75 & - \\
\hline Dehydroascorbic acid dimer (2 MEOX) & 27.4 & $2.86 \mathrm{E}+09$ & NA & $4.90 E+09$ & $3.98 \mathrm{E}+09$ & NA & $1.62 E+09$ & 0.72 & - \\
\hline Phenylalanine (2 TMS) & 22.6 & $1.34 \mathrm{E}+08$ & $7.28 \mathrm{E}+07$ & $1.93 \mathrm{E}+08$ & $1.34 \mathrm{E}+08$ & $5.57 \mathrm{E}+07$ & $9.40 \mathrm{E}+07$ & 0.71 & 0.41 \\
\hline Phosphohexose (tentative) & 36.6 & $1.35 \mathrm{E}+09$ & NA & $2.29 E+09$ & $9.73 \mathrm{E}+08$ & NA & $1.59 \mathrm{E}+09$ & 0.70 & - \\
\hline Disaccharide derived acid (tentative) & 30.4 & $3.36 \mathrm{E}+09$ & $2.31 \mathrm{E}+09$ & $5.54 \mathrm{E}+09$ & $4.19 \mathrm{E}+09$ & $1.06 \mathrm{E}+09$ & $2.64 \mathrm{E}+09$ & 0.70 & 0.45 \\
\hline Mannose (1)(1 MEOX) (5 TMS) & 28.2 & $3.05 E+07$ & $1.05 \mathrm{E}+07$ & $3.40 \mathrm{E}+07$ & $1.95 \mathrm{E}+07$ & $9.74 \mathrm{E}+06$ & $2.26 \mathrm{E}+07$ & 0.69 & 0.41 \\
\hline Ribonic acid (tentative) (5 TMS) & 25.4 & $2.58 \mathrm{E}+09$ & NA & $2.44 \mathrm{E}+09$ & $2.01 \mathrm{E}+09$ & NA & $1.37 \mathrm{E}+09$ & 0.67 & - \\
\hline Citric acid (4 TMS) & 26.9 & $5.73 E+10$ & $2.22 \mathrm{E}+10$ & $6.83 E+10$ & $5.18 \mathrm{E}+10$ & $1.73 E+10$ & $2.79 \mathrm{E}+10$ & 0.66 & 0.38 \\
\hline Malic acid (3 TMS) & 19.3 & $8.51 \mathrm{E}+10$ & $3.03 E+10$ & $1.59 \mathrm{E}+11$ & $1.08 \mathrm{E}+11$ & $2.66 \mathrm{E}+10$ & 4.47E+10 & 0.65 & 0.52 \\
\hline Unknowm RT 11.57 & 11.6 & NA & $1.78 \mathrm{E}+08$ & $5.71 \mathrm{E}+09$ & $1.00 \mathrm{E}+09$ & NA & $2.58 \mathrm{E}+09$ & 0.61 & - \\
\hline Unknown RT 25.01 & 25.0 & $4.52 E+09$ & NA & $3.05 E+10$ & $7.44 \mathrm{E}+09$ & $2.88 \mathrm{E}+09$ & $2.11 \mathrm{E}+10$ & 0.60 & - \\
\hline Isoleucine (2 TMS) & 14.2 & $1.15 E+10$ & $5.95 E+09$ & $1.98 \mathrm{E}+10$ & $4.43 E+08$ & $6.11 \mathrm{E}+09$ & $1.49 \mathrm{E}+10$ & 0.58 & 0.42 \\
\hline Saccharide (tentative) & 32.1 & NA & NA & $1.51 \mathrm{E}+09$ & $1.01 \mathrm{E}+09$ & $6.04 \mathrm{E}+08$ & NA & 0.53 & - \\
\hline Sucrose (8 TMS) & 41.4 & $2.44 \mathrm{E}+10$ & $8.02 E+09$ & $2.51 \mathrm{E}+10$ & $1.53 E+10$ & $7.08 \mathrm{E}+09$ & $6.94 \mathrm{E}+09$ & 0.51 & 0.21 \\
\hline Disaccharide & 41.9 & $1.35 E+12$ & $4.07 \mathrm{E}+11$ & $1.36 \mathrm{E}+12$ & $8.15 E+11$ & $3.29 \mathrm{E}+11$ & $3.98 \mathrm{E}+11$ & 0.49 & 0.21 \\
\hline Raffinose (11 TMS) & 51.8 & $6.40 E+09$ & $1.18 \mathrm{E}+09$ & $7.62 E+09$ & $3.54 E+09$ & $1.57 E+09$ & $1.72 \mathrm{E}+09$ & 0.45 & 0.25 \\
\hline Fructose (5 TMS) & 26.7 & $2.52 E+09$ & NA & $3.08 E+09$ & NA & $5.53 \mathrm{E}+08$ & NA & 0.20 & - \\
\hline
\end{tabular}

Analyte abundances were calculated as integrated peak areas; $t_{R}$, retention time; (tentative) indicates tentative identification; the order of metabolites in the table corresponds to the descending values of fold changes; NA-not detected. 


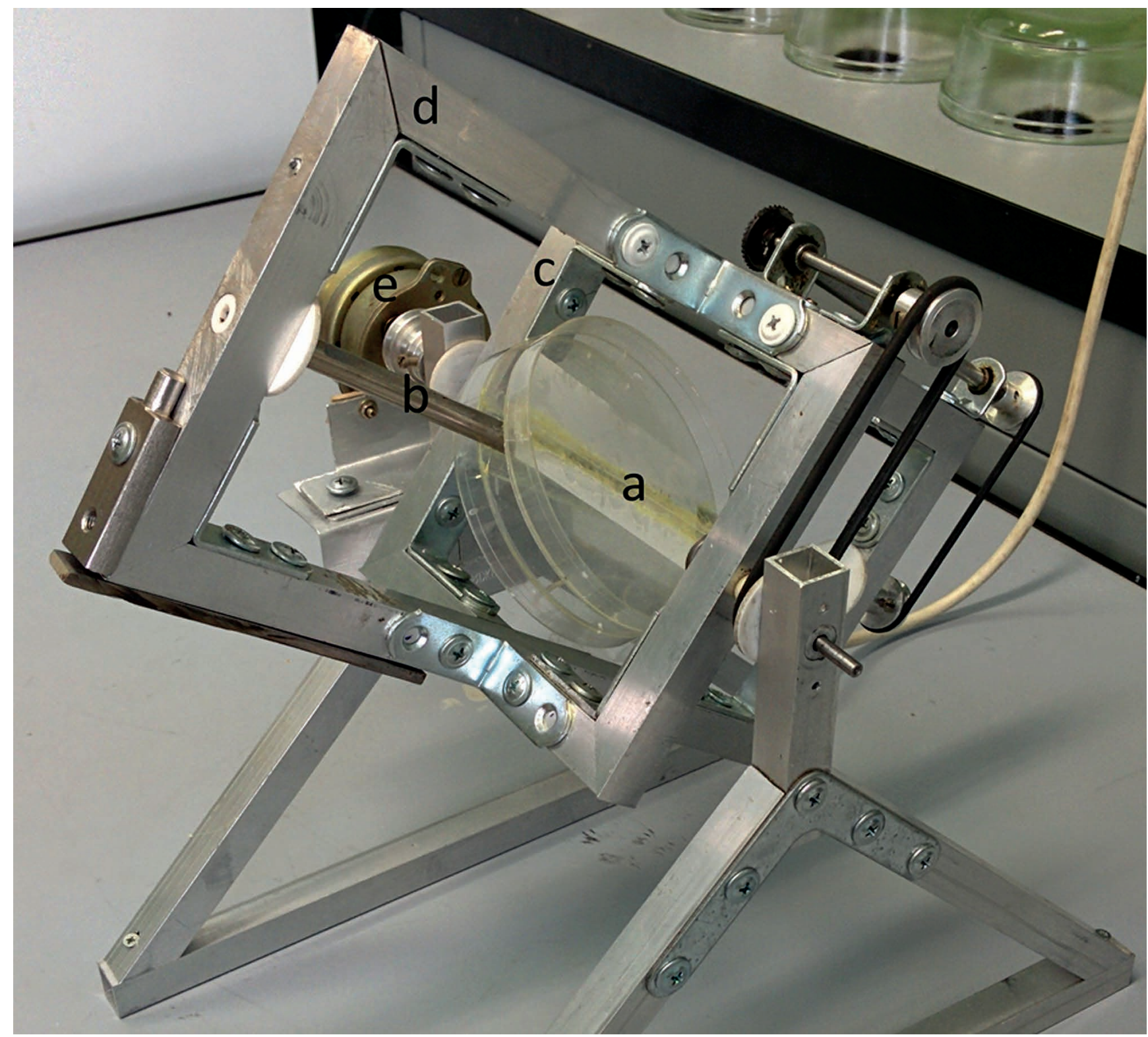

Fig. S-1. 3D-clinostat used to analyze the effects of microgravity on seed germination: $\mathbf{a}$, insert for Petri plates; $\mathbf{b}$, rotating shaft; c, inner frame; d, outer rotating frame; e, motor. 

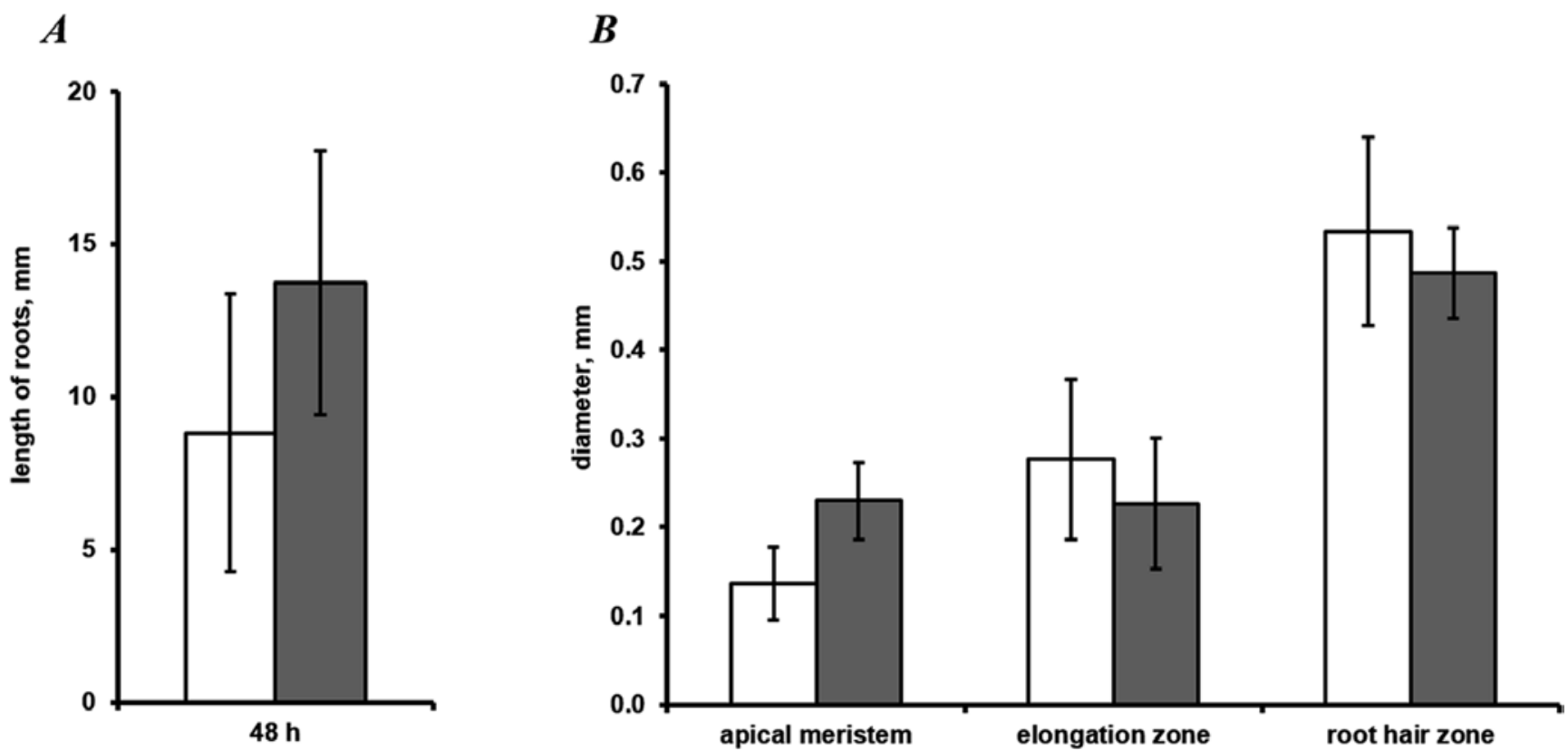

Fig. S-2. Morphological parameters of 48-h-old seedlings germinated under static conditions (control, white) and in the presence of clinorotation (grey): roots length (A) and thickness (B), expressed as root diameter. 